\title{
Basal cell carcinoma: biology, morphology and clinical implications
}

\author{
A Neil Crowson ${ }^{1,2}$ \\ ${ }^{1}$ Departments of Dermatology, Pathology and Surgery, University of Oklahoma, Tulsa, OK, USA and \\ ${ }^{2}$ Regional Medical Laboratory, St John Medical Center, Tulsa, OK, USA
}

\begin{abstract}
Basal cell carcinoma (BCC) is the most common malignant neoplasm of humans. Rising dramatically in incidence in North America, as likely reflects changing habits of the population and a move from more northerly climes to the sunbelt of the Southern and Southwestern United States, the incidence is surely to rise even higher in the future. The last decade has seen significant advances in our understanding of BCC biology and novel approaches to therapy, which hinge upon accurate diagnosis and subclassification by pathologists. The purpose of this review article is to summate the research advances in our understanding of BCC biology and to acquaint pathologists and clinicians to the practical issues in BCC diagnosis and subclassification which flow there from.

Modern Pathology (2006) 19, S127-S147. doi:10.1038/modpathol.3800512
\end{abstract}

Keywords: basal cell carcinoma; biology; histology; ultrastructure

\section{Introduction}

Basal cell carcinoma (BCC), first described by Jacob in $1827,{ }^{1}$ is the most common malignant neoplasm of humans. ${ }^{2-4}$ After a rise in incidence of roughly $20 \%$ between 1971 and $1977,{ }^{5}$ by 1998 roughly one million new cases were being diagnosed annually in the United States. ${ }^{6}$ In consequence of its high incidence, BCC, although eminently curable when the diagnosis is made promptly and the lesion treated in its early phase, constitutes an enormous financial burden on the health care system.

Lesions occur on both sun-protected and sunexposed skin, but often have a different biology and morphology in these locations. ${ }^{7}$ Typically, BCCs occur in the fourth decade of life and beyond ${ }^{8}$ although exceptions to this occur, in particular in the setting of specific genodermatoses or in patients with immune compromise. ${ }^{9}$ As sun exposure plays a role in the development and transformation of BCC, ${ }^{7}$ patients with light skin phenotypes are particularly predisposed as expected; this includes in the context of blue eyes, red hair and easy freckling ${ }^{8}$ as well as those whose occupational or leisure activities lead them to pronounced and prolonged

Correspondence: AN Crowson, MD, Regional Medical Laboratory, St John Medical Center, 1923 S Utica Street, Tulsa, OK 741144109, USA.

E-mail: ncrowson@sjmc.org

Received 16 September 2005; accepted 28 September 2005 sun exposure. Additional risk factors for BCC include the exposure to arsenic, coal tar derivatives and irradiation, although by far ultraviolet (UV) light is the most important factor in lesion development and progression. ${ }^{5,7,8,10,11}$ BCC may, like squamous cell carcinoma, arise in the setting of scars, draining sinuses, ulcers, burn sites and foci of chronic inflammation..$^{8,10,11}$ The role of immune compromise in provoking an increased risk of BCC may be due to impairment of the immune surveillance of oncogenic viruses. ${ }^{12}$ The genodermatoses that enhance the risk of BCC include the prototype xeroderma pigmentosa, Rasmussen syndrome, Rombo syndrome, Bazex-Christol-Dupre syndrome, albinism and Darier's disease. ${ }^{5,11,13}$ These syndromes variably either decrease epidermal pigmentation and thus increase the risk of UV light-induced oncogenic transformation ${ }^{7}$ or promote genotypic instability in the epidermis.

BCC has been associated with a variety of other lesions and/or neoplasms in the same or a nearby anatomic location. For example, desmoplastic trichilemmoma is said to be associated with coexistent atypical basaloid neoplasms including BCC in up to $19 \%$ of cases $;{ }^{14}$ the aforementioned study shows the impact of selection bias as it was based first on the detection of the coincidence of BCC and desmoplastic trichilemmoma followed by a retrospective analysis of all accessioned desmoplastic trichilemmomas over a set time interval. Other lesions associated with coexistent BCCs include acantholytic processes of diverse type (personal observation), 
warts, porokeratosis, neurofibromata, nevi sebaceus and epidermal nevi, condylomata accuminata, hemangiomas, cysts of hair follicle derivation, pilomatricomas and a variety of common skin neoplasms such as seborrheic keratoses and melanocytic nevi, which are so common as to make their coexistence with BCC in any given patient a random event in all probability. ${ }^{8,11,13,14}$ Basal cell carcinomata have also been reported in collision with a common dermal fibrosing reaction to trauma (ie dermatofibroma), but in this setting the presence of dermal proplastic cytokines could explain the epidermal proliferation. As in nevi sebaceus, the basaloid epidermal proliferation overlying a dermatofibroma often shows a form of follicular stromal induction suggesting a recapitulation of hair follicle growth. Whether a component of a hamartoma or as a response to proplastic cytokines, it is not clear that such basaloid proliferations frequently have a propensity to eventuate in a malignant neoplasm with the capacity for local tissue invasion or destruction or, ultimately, of metastatic events. Before considering the pathogenesis of BCC, it is first necessary to define the clinical characteristics and their corresponding histologic expression.

\section{Clinical Features}

The typical BCC is a pearly pink or flesh colored papule with telangiectasia. Lesions may be translucent or slightly erythematous with a rolled border (Figure 1), occasionally accompanied by bleeding, scaling or crusting. Aggressive growth tumors tend to show more frequent ulceration and large, untended neoplasms can be locally destructive of eyes, ears and nares. ${ }^{15}$ The different histomorphologic subgroups have their specific clinical correlates; the aggressive growth variants such as infiltrative (Figure 2) or morpheaform BCC manifest as a depressed scariform plaque while the superficial variant presents as a reddish plaque with variegate depigmentation and a spreading peripheral margin and/or an atrophic or scar-like peripheral border that raises consideration clinically to Bowen's disease, nummular eczema and other annular dermatoses such as superficial fungal infections. ${ }^{11}$ The presence of a surrounding hypo- or hyperpigmented flare has been designated 'halo' BCC, ${ }^{11}$ the histologic correlate of which is a heavy band-like lymphoid infiltrate. Lesions of the superficial variety are frequently multifocal (the so-called 'field fire' basal cell cancer). ${ }^{11}$ The linear variant in childhood and adolescence manifests a longitudinal arrangement. ${ }^{16}$ Apart from presenting with a papule or nodule typically on sun-exposed skin, patients generally have no other complaints referable to the tumor. On rare occasions, a lesion manifests tenderness or pain which can be a clue to perineural infiltration in the aggressive growth varieties. ${ }^{17}$ Sensorimotor compromise has been reported parti-

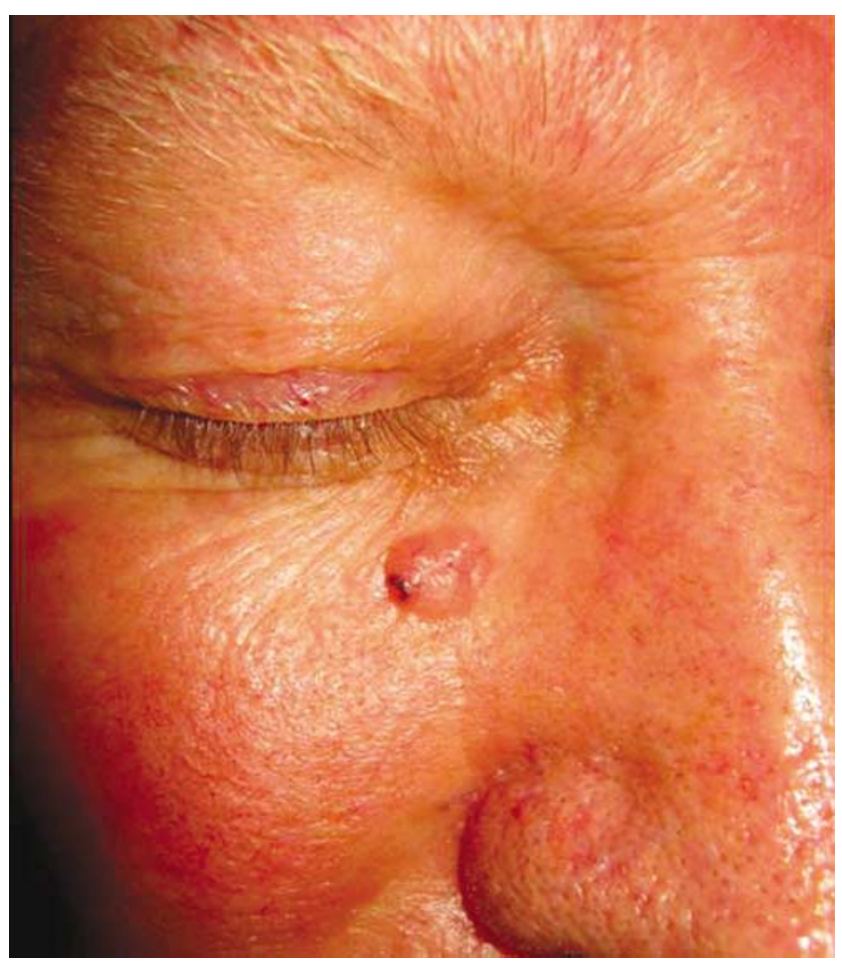

Figure 1 Nodular BCC: clinical morphology. This pearly, nodular lesion shows telangiectasia on its surface and a sharp contour with a smooth margin. An incisional biopsy has been performed. (Case courtesy of Dr George Monks, Tulsa, OK.)

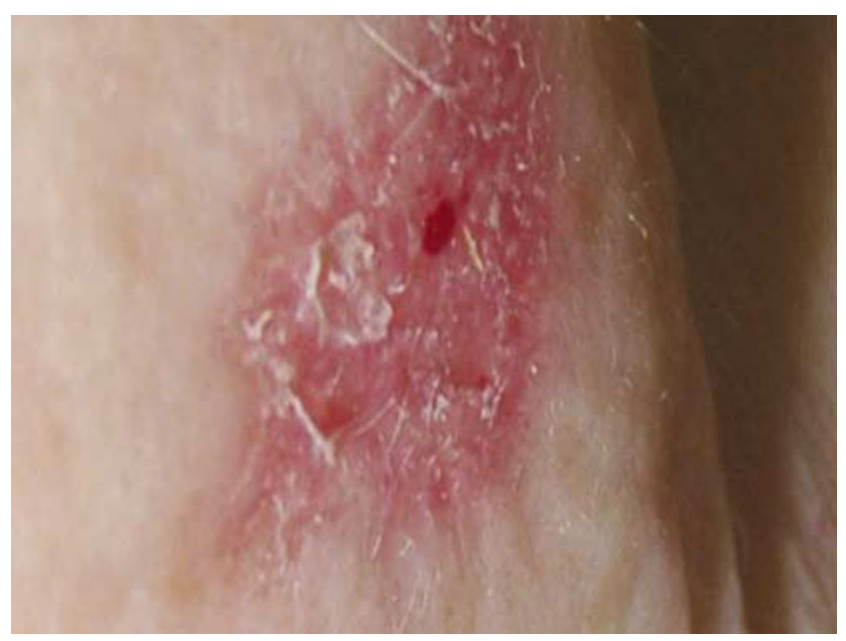

Figure 2 Infiltrative growth BCC: clinical morphology. The infiltrative growth BCC has a scaly surface, a pink to reddish color and an irregular, ill-defined margin. This is a plaque lesion which can be either slightly elevated or depressed with palpable induration at the tissue edges. (Case courtesy of Dr Michael Wilkerson, Tulsa, OK.)

cularly in lesions of the preauricular and cheek areas. ${ }^{17}$

Metastases are rare and most are said to more closely correlate to the size and depth and less so to the histologic subtype of the original tumor. ${ }^{18-20}$ Lesions that recur after radiotherapy may infiltrate 
widely prior to becoming clinically apparent; this plus the fact that radiotherapy is often reserved for aggressive growth tumors ought to enhance the suspicion of perineural infiltration in recurrent BCC postirradiation. ${ }^{19}$ The incidence of metastases and/or death is said to correlate to large tumors greater than $3 \mathrm{~cm}$ in diameter in which setting patients are said to have a $1-2 \%$ risk of metastases that increases to up to $20-25 \%$ in lesions greater than $5 \mathrm{~cm}$ and up to $50 \%$ in lesions greater than $10 \mathrm{~cm}$ in diameter. ${ }^{21} \mathrm{~A}$ 'giant' BCC is designated as one that is greater than $5 \mathrm{~cm}$ in diameter and has a significant risk of morbidity and mortality. ${ }^{19,20}$ A BCC arising in a young person (ie less than 35 years of age) may have an aggressive clinical course. ${ }^{19}$

\section{Nevoid BCC (Basal Cell Nevus) Syndrome}

\section{Introduction}

Described originally by Howell and $\mathrm{Caro}^{22}$ in 1959, the nevoid BCC syndrome is also known as the Gorlin-Goltz syndrome ${ }^{23,24}$ and is inherited as an autosomal dominant trait with some $30-50 \%$ of cases representing sporadic mutations. ${ }^{23,24}$ Typi- cally, the syndrome is expressed in young adulthood but on occasion children as young as 2 years of age manifest disease expression characterized by the presence of multiple basal cell cancers and other anomalies as described below. The prevalence is roughly 1 in $56000 .^{8}$ In most cases, the abnormality represents a mutation in the human homologue of the Drosophila patched gene (PTCH) ${ }^{25}$ Perturbation of this tumor suppressor gene on chromosome 9 q22-q31 $1^{26,27}$ results in upregulated cell proliferation. The biology of sporadic BCC and of tumors arising in the setting of nevoid BCC syndrome is discussed in greater detail below.

\section{Clinical features}

The clinical manifestations of nevoid BCC syndrome include the presence of numerous (up to thousands) of BCCs (Figure 3), ${ }^{24}$ in essence similar to those which occur sporadically in the population but with an emphasis on nodular, superficial, and, in our experience, infundibulocystic types. Patients also manifest cysts of the skin and of the jaws, the latter showing a corrugated eosinophilic internal cuticular lining cognate to odontogenic keratocysts ${ }^{24}$

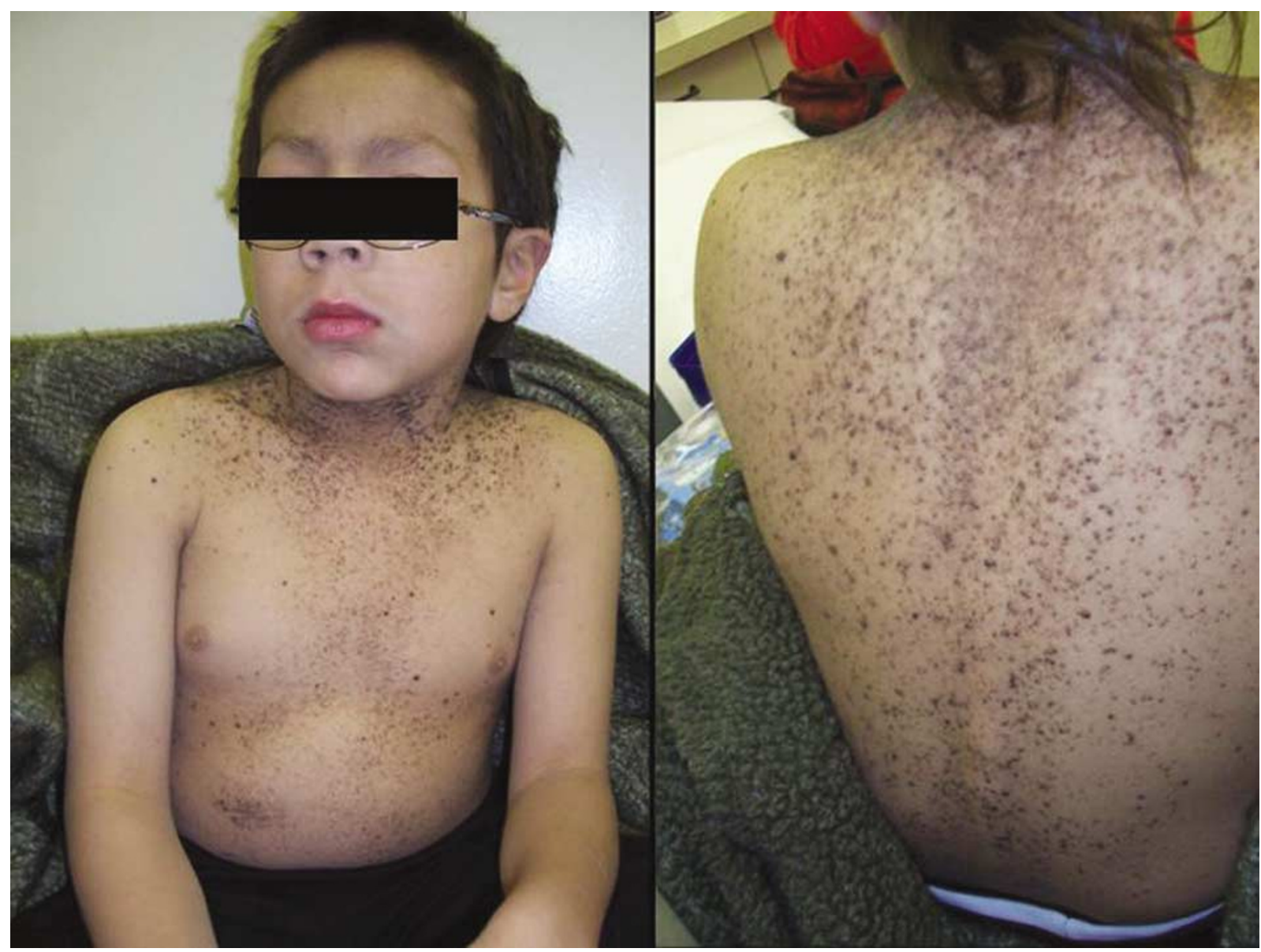

Figure 3 Basal cell nevus syndrome: clinical morphology. This 9-year-old boy with basal cell nevus syndrome has thousands of pigmented papules and skin tag-like lesions on his trunk which correspond histologically to infundibulocystic BCC; the histology of one of these lesions is represented in Figure 12. (Case courtesy of Dr David Adelson, Department of Dermatology, University of Oklahoma.) 
and the former showing a similar eosinophilic internal cuticle as is seen in steatocystomas. ${ }^{28}$ Also present are skeletal anomalies including spinal and rib deformities, excessive ossification with bossing of the frontal skull and bridging of the sella turcica. Calcification of the falx cerebri is another manifestation. ${ }^{10,24}$ Palmoplantar pits typically $1-3 \mathrm{~mm}$ in depth and $2-3 \mathrm{~mm}$ in diameter appear during the second decade of life. ${ }^{29}$ Neuropsychiatric impacts include schizophrenia, abnormal electroencephalograms, mental retardation and cerebellar degeneration..$^{30}$ Some patients manifest tumors and other anomalies of the reproductive system.

\section{Histopathology}

The histology of most BCCs encountered in the nevoid BCC syndrome are, as mentioned, typically not dissimilar from those seen in sporadic BCCs. The epidermal cysts are usually derived from the follicular infundibula with a pronounced keratohyalin granular layer in the internal squamous epithelial lining while in some cases the histology is more cognate to steatocystomata but differs by the absence of sebaceous glands. ${ }^{28}$

\section{Differential diagnosis}

Although one can generally not tell from a single biopsy that a patient does or does not have basal cell nevus syndrome, the astute pathologist will suspect the diagnosis when an individual in the second or third decade of life has a BCC in a biopsy submitted with no clinical information. Multiple tumor syndromes that can produce basaloid adnexal neoplasms include Muir-Torre syndrome and Cowden's syndrome but these produce neoplasms with sebaceous and trichilemmal differentiation, respectively. The cystic structures will resemble steatocystoma multiplex congenita while dermoid cysts show pilosebaceus differentiation, sometimes with eccrine or apocrine glands and frequently with true follicular differentiation including in the context of hair shaft production. The cutaneous pits of pitted keratolysis manifest Gram positive filamentous or rounded bacteria in the cornified layer.

\section{Histopathology of BCC}

\section{Introduction}

Traditionally, BCCs have been classified as solid (or undifferentiated) $v s$ those tumors that manifest specific differentiation features (ie to eccrine, sebaceous or other cell lines). However, the only proven histologic prognosticator of biologic behavior, and therefore a major determinant of what constitutes an appropriate therapeutic approach, is the architectural growth pattern. Thus, the architecture is a critical issue, while the differentiation patterns need to be considered only insofar as they must be recognized as part of the histologic spectrum of BCC, and as they impact differential diagnosis. Their misidenti- fication as Merkel cell carcinoma or as sebaceous, eccrine, or follicular neoplasia is a diagnostic pitfall that carries with it a risk of over- or undertreatment.

One needs to be aware that shave and punch biopsy specimens have an intrinsic error rate, due to the nature of the tissue sample, of roughly $20 \%$ in predicting classification of BCC subtypes when compared to completion excisions at the same anatomic location. ${ }^{31}$ The reason for this may be explained by the fact that biological transformation of BCC tends to occur at the base and edges of the growing neoplasm.

\section{The Undifferentiated BCCs}

\section{Introduction}

We classify BCCs as belonging to indolent-growth or aggressive-growth subsets. The indolent-growth variants include superficial and nodular BCC. The aggressive growth tumors are infiltrative BCC, metatypical BCC, and morpheiform or sclerosing BCC. ${ }^{7}$ In one large retrospective series of 1039 consecutive neoplasms, and using a slightly dissimilar classification scheme, $21 \%$ were nodular, $17.4 \%$ were superficial, $14.5 \%$ were micronodular, $7.4 \%$ were infiltrative and $1.1 \%$ were morpheiform. ${ }^{32}$ Roughly one-third of all tumors showed an admixture of patterns. ${ }^{32}$

\section{Superficial BCC}

Superficial BCC is characterized by a proliferation of atypical basaloid cells that form an axis parallel to the epidermal surface and demonstrate slit-like retraction of the palisaded basal cells from the subjacent stroma (Figure 4). ${ }^{7}$ The resulting cleft-like spaces often contain alcian blue-positive mesenchymal mucoid material, a presumed product of the stromal cells. Tumor cells may colonize the hair follicle and rarely the eccrine adnexal structures and, as mentioned above, often take origin from the follicular bulges. Mitoses are infrequent and apoptic cells rare in the atypical basaloid buds for reasons reflecting their biologic derivation as described below. Some cases manifest melanin pigmentation of the epithelium and in the histiocytes in the subjacent stroma; of pigmented BCCs, most are held to reflect superficial tumors in some series, ${ }^{32}$ although in our experience nodular BCCs constitute by far the most frequent form of pigmented BCC. A band like, often heavy, lymphoid infiltrate may be present. When seen in the setting of a biopsy for suspect superficial or superficial multifocal BCC, a band-like lymphoid infiltrate should prompt a careful search through multiple levels looking for foci of superficial BCC.

\section{Nodular BCC}

Nodular BCC represents the most common form of the neoplasm in our experience. Nodular BCC is also referred to as nodulocystic BCC by some observers, 


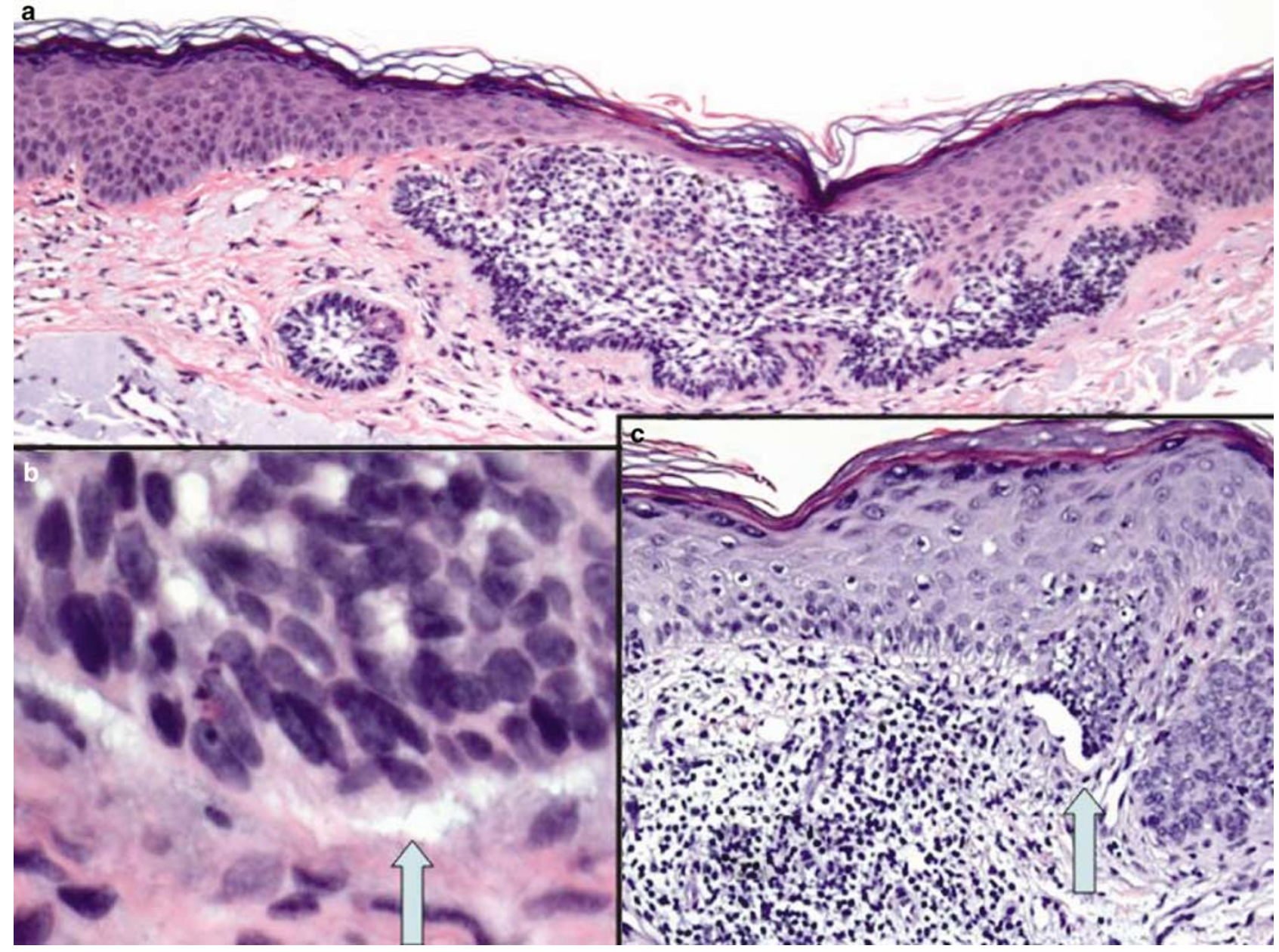

Figure 4 Superficial BCC: histomorphology. (a) A proliferation of basaloid cells parallel to the long axis of the epidermis. Serial sectioning showed the small nest at left to connect to the remainder of the tumor, which is in continuity with the undersurface of the epidermis (a). (b) Slit-like stromal retraction (arrow) with mucin deposition in the papillary dermis. (c) A band-like lymphoid infiltrate in apposition to the basaloid nests (arrow) and the undersurface of the epidermis. If only the band-like lymphoid infiltrate is present in a biopsy intended to confirm the presence of BCC, serial deeper step sections through the tissue block are advised.

although this term is not employed by us. This is the type of BCC that clinically shows a translucent pearly papule or nodule with a rolled border and telangiectasia (Figure 1). The nodular form of BCC is characterized by discrete large or small nests of basaloid cells in either the papillary or reticular dermis accompanied by slit-like retraction from a stroma in which the fibroblasts do not appear to be plump or proplastic (Figure 5). Any of the differentiated elements (eccrine, sebaceous, etc) may be seen in nodular tumors and roughly one-third of cases will show a coexistent superficial component. As both superficial and nodular BCC can be seen in sun-exposed or sun-protected skin, the dermis may show solar elastosis and this may be pronounced. The surrounding stroma shows myxoid change, is rarely fibrotic and may show calcification in discrete islands of tumor or in adjacent stroma. Mitoses and individual cell necrosis are uncommon. The presence of abundant slit-like retraction may cause tumor nests to drop out from the stroma during processing yielding empty spaces with a rounded contour in the mid or deep dermis (Figure 6). This is an important clue to the diagnosis in the setting of the nodular and/or infiltrative growth patterns. ${ }^{33}$ A significant proportion of BCCs with a nodular component manifests a variable admixture of superficial and/or micronodular morphologies. ${ }^{32}$

Melanin pigmentation of tumor cells and adjacent stromal histiocytes may be seen. Transition to micronodular and other aggressive growth forms of BCC may be seen.

\section{Micronodular BCC}

Micronodular BCC manifests a plaque-like indurated lesion with a poorly demarcated contour. ${ }^{34}$ As mentioned above, lesions may be difficult to remove and so have an increased incidence of recurrence. ${ }^{32,35}$ Micronodular BCC manifests tumor nests with roughly the same shape and contour as nodular BCC, but which are nonetheless smaller and widely dispersed in an often asymmetric distribution 


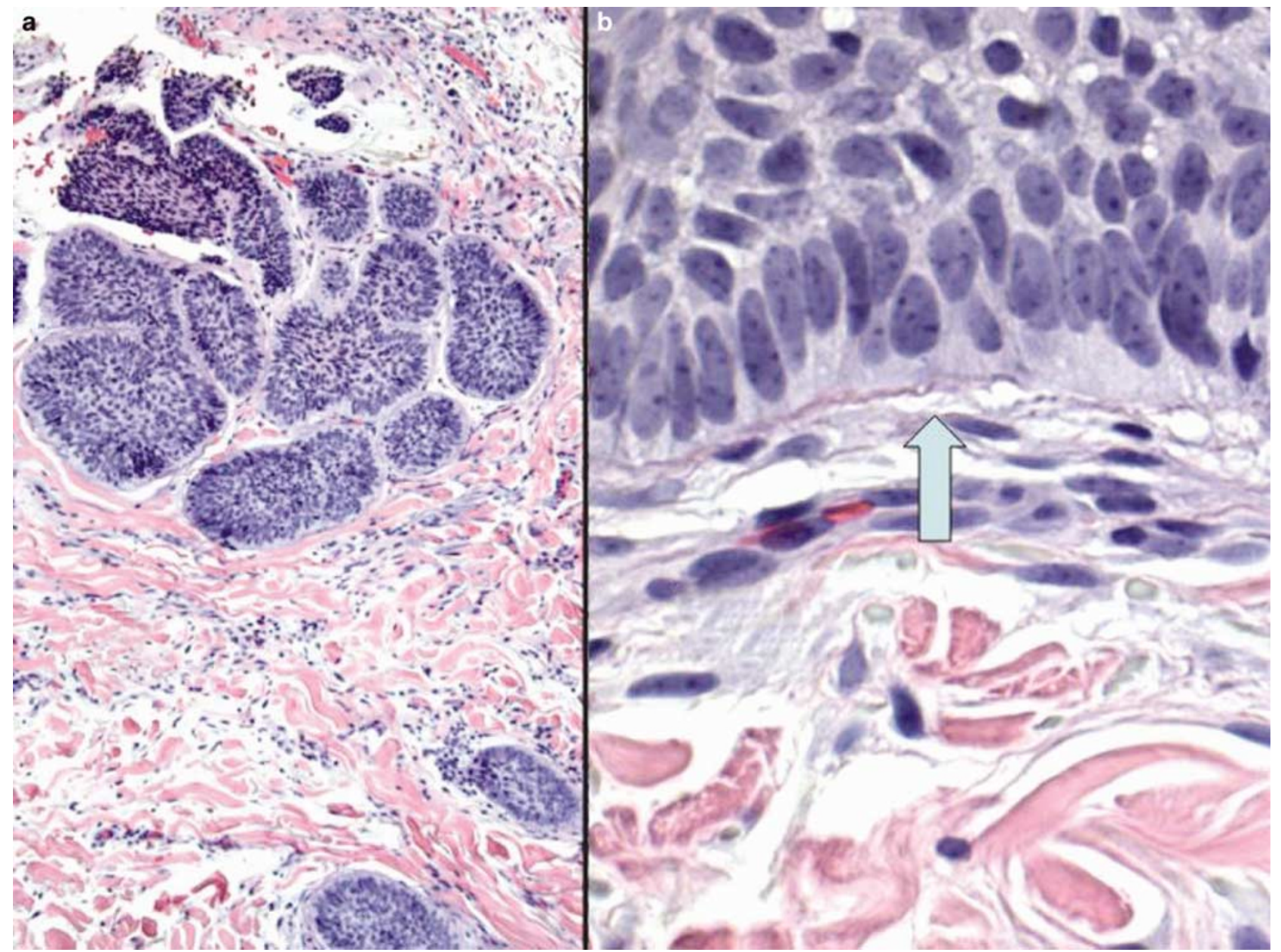

Figure 5 Nodular BCC: histomorphology. Nodular BCC manifests multiple variably sized and rounded nodules with a pushing contour in apposition to a stroma that shows no significant fibroplasias (a). The nodules of tumor show a peripheral palisade of basaloid cells and, at their interface with the stroma, slit-like retraction is seen (arrow) (b). Note also the eosinophilic condensation of basement membrane material adherent to the cytoplasms of the palisading basaloid cells (b).

extending deeper into the dermis and/or subcutis (Figure 7). These monotonous, small round tumor nests are accompanied by stromal proliferation cognate to the infiltrative growth BCC. Retraction spaces are not common and the surrounding stroma shows either a myxoid or collagenized morphology suggesting that these lesions may be an intermediate step between nodular and aggressive growth subtypes. $^{7,32,34}$ The micronodular BCC has been reported to have a higher incidence of local recurrence $^{32,34}$ and may penetrate more deeply into the reticular dermis and/or subcutis.

\section{Aggressive growth BCC}

The aggressive growth BCCs include the prototypic morpheaform BCC, infiltrative growth BCC and metatypical BCC.

\section{Morpheaform BCC}

Morpheaform or sclerosing BCC is characterized by columns of basaloid cells one to two cells thick enmeshed in a densely collagenized stroma containing proplastic fibroblasts (Figure 8). Individual cell necrosis and mitotic activity is brisk considering the relative tumor volume and the neoplasms themselves are poorly demarcated, showing widespread invasion of the reticular dermis and penetration into the subcutaneous tissue. Slit-like retraction from the stroma is less common than for the nodular and superficial variants but is still often demonstrable. These neoplasms may coexist with other aggressive growth morphologic variants. Morpheaform BCCs represent roughly $1-5 \%$ of all BCCs and clinically present as white or yellow depressed fibrotic scars that rarely ulcerate or bleed. ${ }^{8}$ In our experience, these cancers occur mainly in a sun-exposed distribution. ${ }^{7}$ Although typically one to two cells in thickness, cords up to five cells in thickness may be present; the architecture comprises sharp angulation of such cords. Pronounced stromal fibroplasia and fibrosis surrounds the tumor tongues. By electron microscopy, a basal lamina is absent. ${ }^{36}$ 


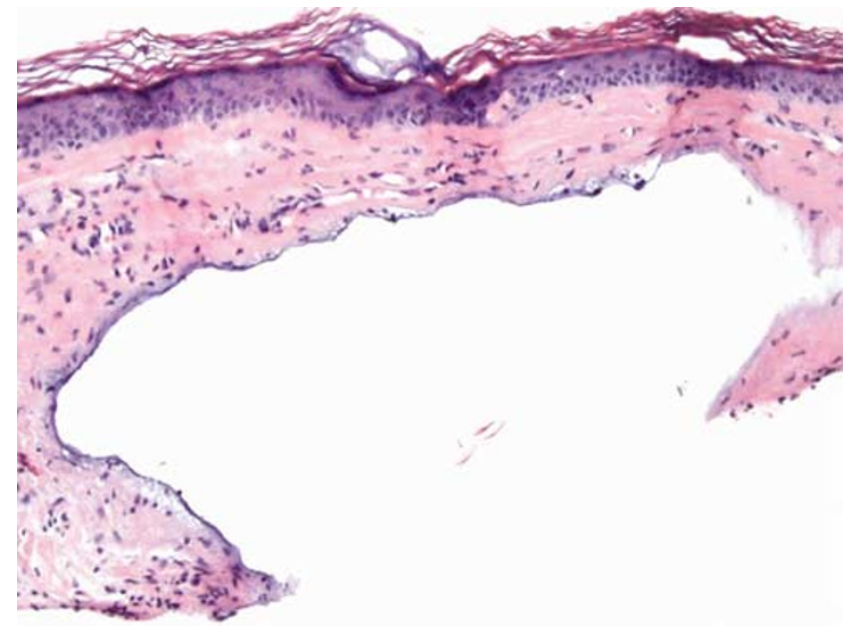

Figure 6 Nodular BCC: histomorphology. The slit-like retraction with mucin deposition in the adjacent stroma causes the nests of BCC to be only loosely adherent to the collagen. Thus, during processing, the tumor cell nests can drop out of the tissue sample, leaving nothing but an empty space, an important clue to BCC.
Infiltrative growth $B C C$

Infiltrative growth BCC comprises, at the light microscopic level, irregularly sized and shaped nests of tumor cells; the nests show sharp angulation of their peripheral contours, occasional foci of slit-like retraction, and frequent mitotic activity and individual cell necrosis of the neoplastic cells (Figure 9). The stroma is frequently fibrotic with plump proplastic stromal fibroblasts. The nests are variable in size and shape with jagged contours. ${ }^{14,32,37}$ Typically the elongated tumor cell strands of the infiltrative growth component are 58 cells in thickness. Roughly one-third of such cases show an admixed nodular component from which the lesions are held to derive following UV irradiation (Figure 10). ${ }^{38}$ Like the morpheaform variant, these tumors are poorly circumscribed and may show invasion of subcutis and adjacent muscular and other structures. Perineural infiltration is a distinct risk in this variant as in the morpheaform BCC, and, like the morpheaform variant, the clinical

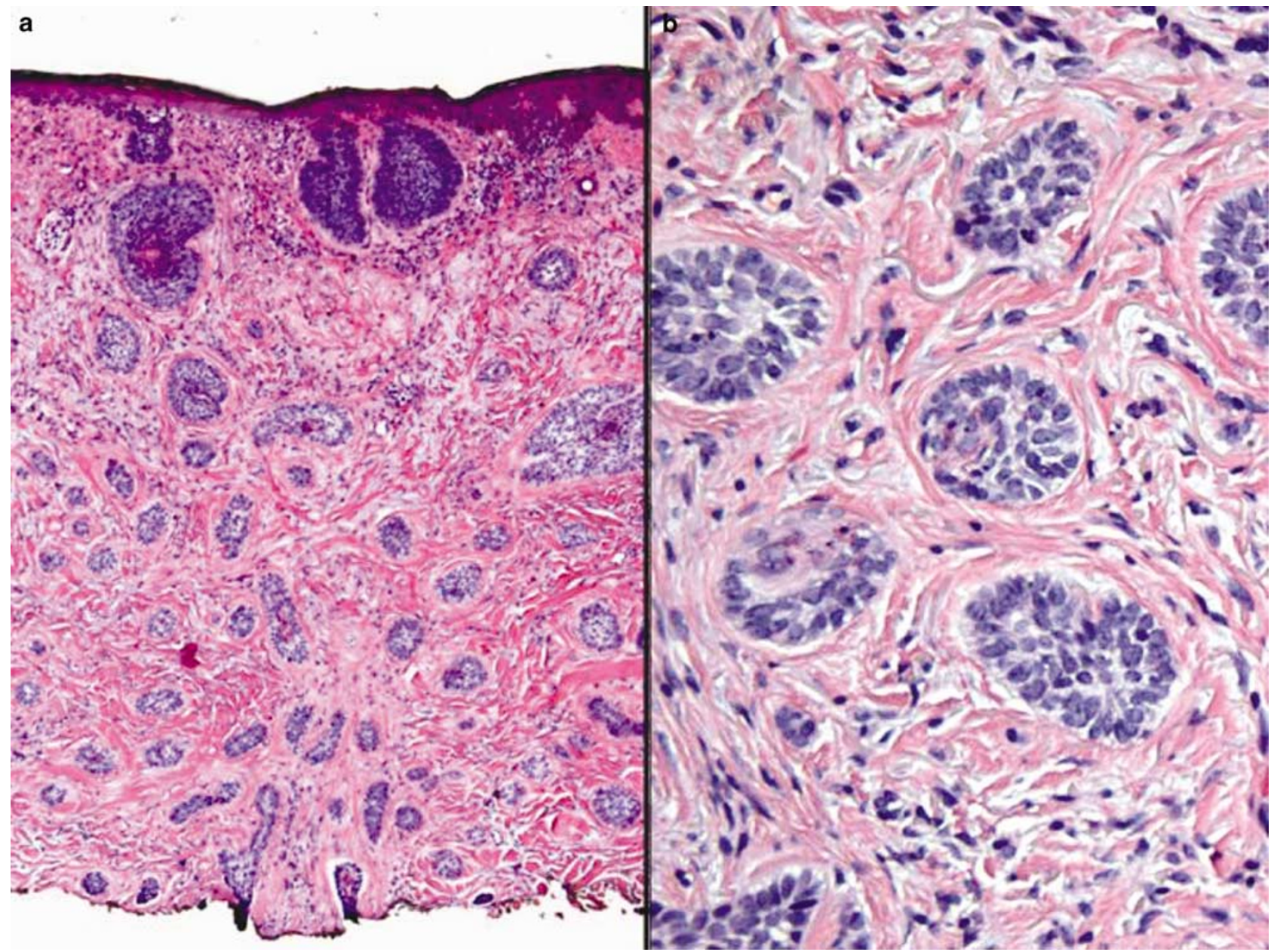

Figure 7 Micronodular BCC: histomorphology. Micronodular BCC manifests uniformly small nests of neoplastic basal cells with rounded peripheral contours extending widely throughout the sampled dermis (a). The adjacent stroma shows fibroplasia (b) indicating a transition step in evolution from nodular to aggressive growth BCC. 
correlate is a depressed yellowish or fibrotic plaque that typically lacks a rolled border or an elevated pearly nodule unless a nodular BCC component coexists.

\section{Metatypical BCC}

The metatypical BCC (equated by some authors with 'basosquamous carcinoma' ${ }^{39}$ ) is, in our view, a form of aggressive growth BCC with infiltrating jagged tongues of tumor cells, some of which manifest an abortive peripheral palisade and clearcut basaloid morphology, admixed with other areas that show intercellular bridge formation and/or cytoplasmic keratinization (Figure 11). Clinching the diagnosis is the presence of a coexistent classic nodular or

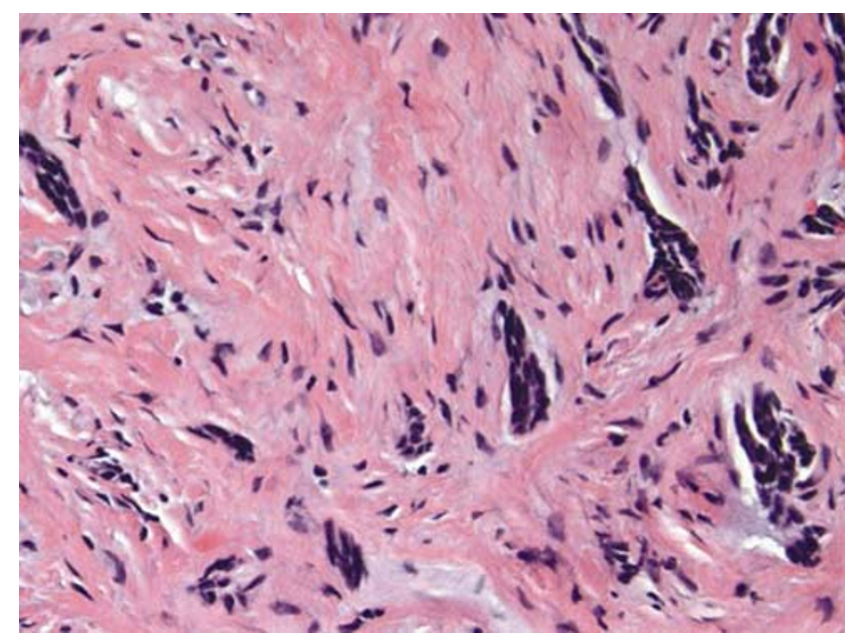

Figure 8 Morpheaform (sclerosing) BCC: histomorphology. In a densely proplastic and heavily collagenized stroma, small irregular (sharply angulated) tongues of neoplastic basaloid cells, often 1-4 cells thick, are embedded in the collagen table. Slit-like retraction may be much less conspicuous than that seen in this particular example. superficial component. We distinguish these neoplasms from keratotic BCC, which is most often a nodular BCC with central squamous differentiation, and from the mixed basal cell-squamous cell carcinomas that represent a collision between two clonally distinctive and geographically separate neoplasms in the same biopsy or excision specimen. Metatypical BCC is the subtype of BCC that can be confused with squamous cell carcinoma and which promotes controversy considering its precise histomorphologic classification,,$^{39,40}$ as it shows both basal cell and squamous cell carcinoma differentiation in a continuous fashion. ${ }^{15,41}$ One must recognize that use of the terms 'metatypical BCC' and

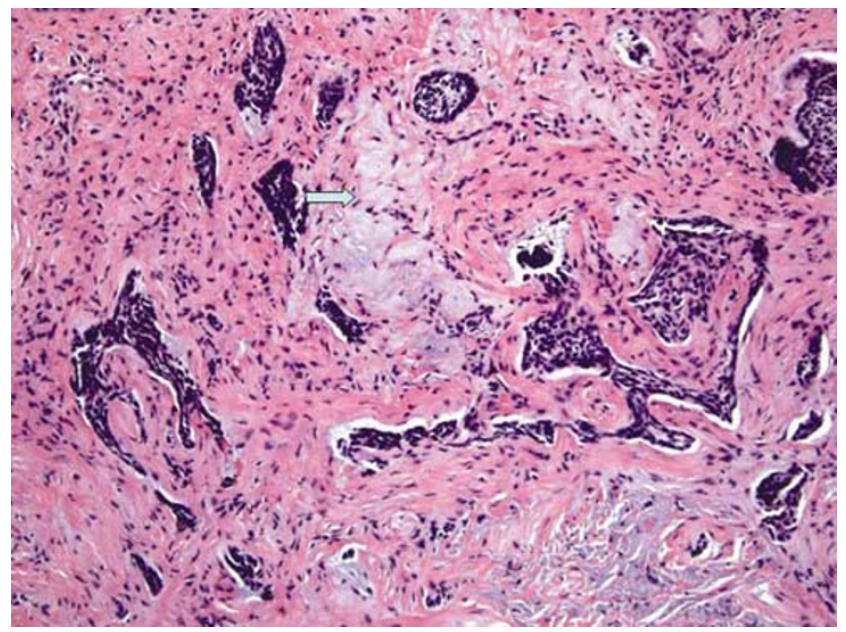

Figure 9 Infiltrative growth BCC: histomorphology. Like morpheaform BCC, the infiltrative growth BCC shows heavy stromal collagenization and proplasia of stromal fibroblasts. However, the tumor tongues manifest an admixture of rounded nodules, large nodules with irregular contours and small irregular tongues of tumor cells embedded in the fibrous stroma. These lesions almost invariably arise in sun-damaged skin, the morphologic evidence of which is solar elastosis (arrow).
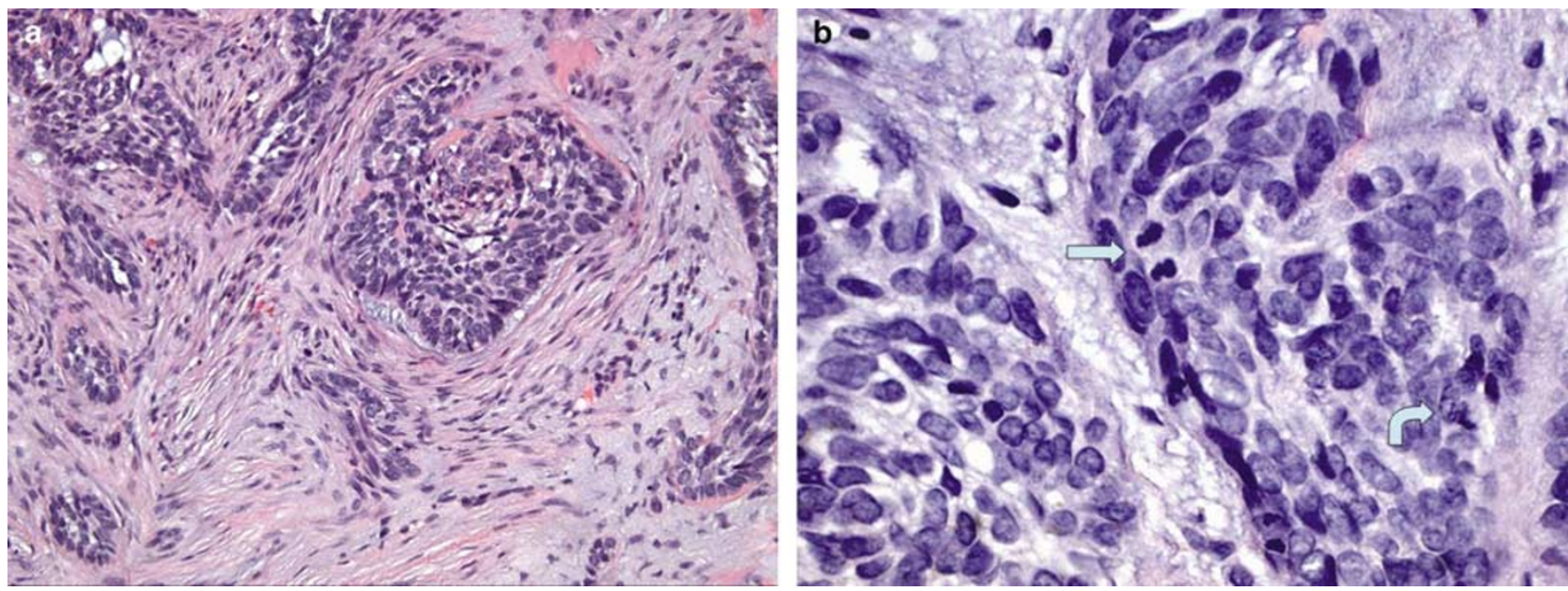

Figure 10 Mixed nodular and infiltrative growth BCC. There is an admixture of rounded and irregularly contoured tumor cell nests embedded in a fibrous stroma. In our experience, this is a very common histologic form of BCC (a). In (b), higher power microscopy shows the presence of mitotic figures (arrow) and apoptotic nuclear debris (curved arrow), which characterizes the aggressive growth BCCs. 


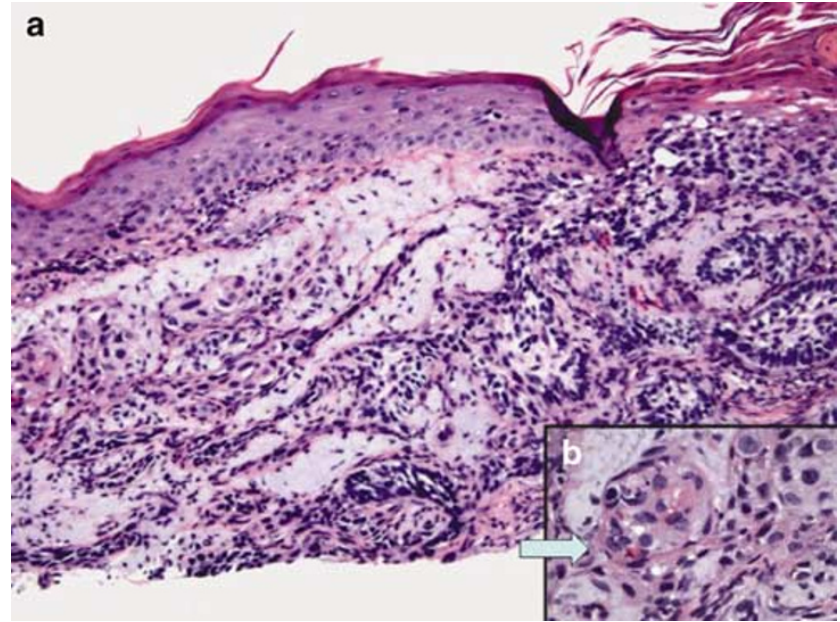

Figure 11 Metatypical BCC: histomorphology. The metatypical BCC is an aggressive growth neoplasm arising in sun-damaged skin and showing irregular tongues of tumor and/or an admixed nodular BCC component (a). High-power microscopy shows cytoplasmic keratinization and/or intercellular bridges in the squamous areas (arrow) (b).

'basosquamous carcinoma' delineates a largely semantic distinction with the proviso that the clinician recognizes what the pathologist is referring to and also that the diagnosis has a specific clinical implication. In summation, in our hands 'metatypical' and 'basosquamous' carcinoma are used synonymously.

\section{The Differentiated BCCs}

\section{Introduction}

BCCs may show a variety of specific cell lineage differentiation features that do not impact prognosis. These include, but are not restricted, to keratotic BCC, ${ }^{39}$ infundibulocystic BCC (Figure 12), ${ }^{42,43}$ follicular BCC, ${ }^{4-47}$ which shows collision features with pilomatricoma, pleomorphic BCC (Figure 13), ${ }^{48,49}$ BCC with eccrine differentiation, ${ }^{50-52}$ BCC with sebaceous differentiation, the fibroepithelioma of Pinkus (Figure 14), ${ }^{53}$ and the BCC with myoepithelial differentiation. ${ }^{54}$

\section{Keratotic BCC}

Also known as pilar BCC as it appears to differentiate along pilosebaceous lines, the keratotic BCC manifests large basaloid tumor nests that are rounded and show central keratinization and degeneration. We deem these to represent a variant of nodular BCC. The central cysts typically lack a granular cell layer and are filled with keratin and parakeratotic debris; a granular cell layer is present in some cases and the cysts may show central calcification surrounded by the basaloid tumor cells. As with other nodular BCCs, the stroma is neither proplastic nor highly collagenized, and mitotic activity is minimal as is the presence of

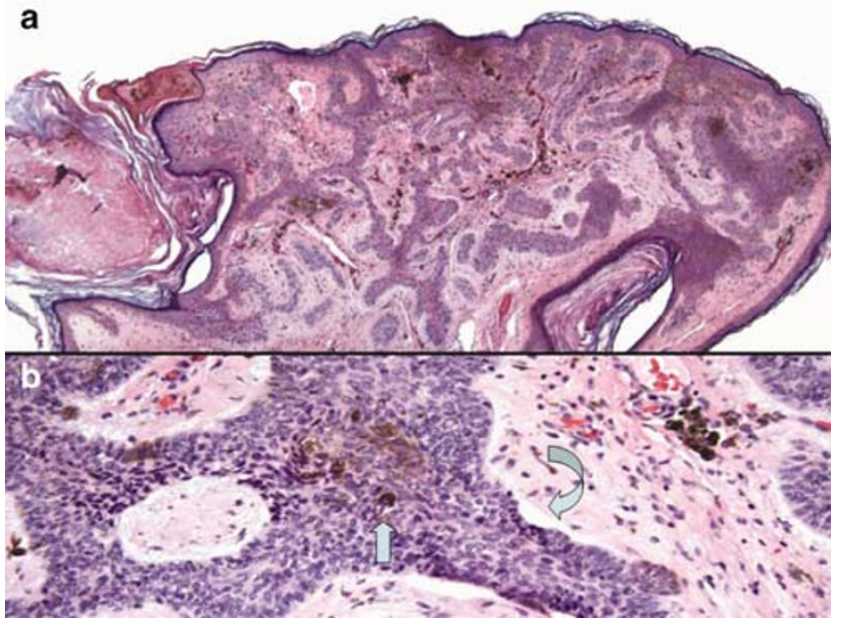

Figure 12 Infundibulocystic BCC: histomorphology. In a skin taglike growth removed from the young patient illustrated in Figure 3 , a polypoid surface contour is noted (a); basaloid tumor tongues are in continuity with the undersurface of the epidermis at multiple points. The individual tumor nests show cytoplasmic melanization (arrow) (b), an important criterion separating BCC from trichoepithelioma and trichofolliculoma. Classical slit-like stromal retraction is seen (curved arrow).

individual cell necrosis. ${ }^{39}$ True hair production is absent.

\section{Infundibulocystic BCC}

In the infundibulocystic BCC, proliferating basaloid cells, typically in continuity with the overlying epidermis, proliferate as oblong and rounded nests surrounding keratin-filled structures lined by a stratified epithelium that shows a granular cell layer. The cells that line these keratin-filled cysts manifest progressive squamoid differentiation with an outer basaloid rim. Follicular bulbs, dermal papillae and papillary mesenchymal bodies typical of true follicular differentiation, and often seen in the trichoepitheliomata, are typically absent. Hair shaft production is not seen. Although the surrounding stroma contains plump cells of presumed fibroblastic lineage and shows minimal myxoid change $;^{42}$ the circumscribed, well demarcated and differentiated stroma of a trichoepithelioma is not present nor is there a desmoplastic stromal reaction as typifies the infiltrative growth BCC, which is one differential diagnostic consideration. The other differential diagnostic possibility is a basaloid follicular hamartoma. The basaloid follicular hamartoma manifests abortive hair papillae, is typically centered around a follicle-like structure in continuity with the epidermis and is typically smaller than the infundibulocystic BCC. The infundibulocystic BCC is a tumor held to show differentiation towards the hair follicle infundibulum. A sebaceous component is usually absent. This morphology is seen in lesions associated with a familial pattern of inheritance. We have also seen infundibulocystic BCC in the setting of skin tag-like polypoid growths in 


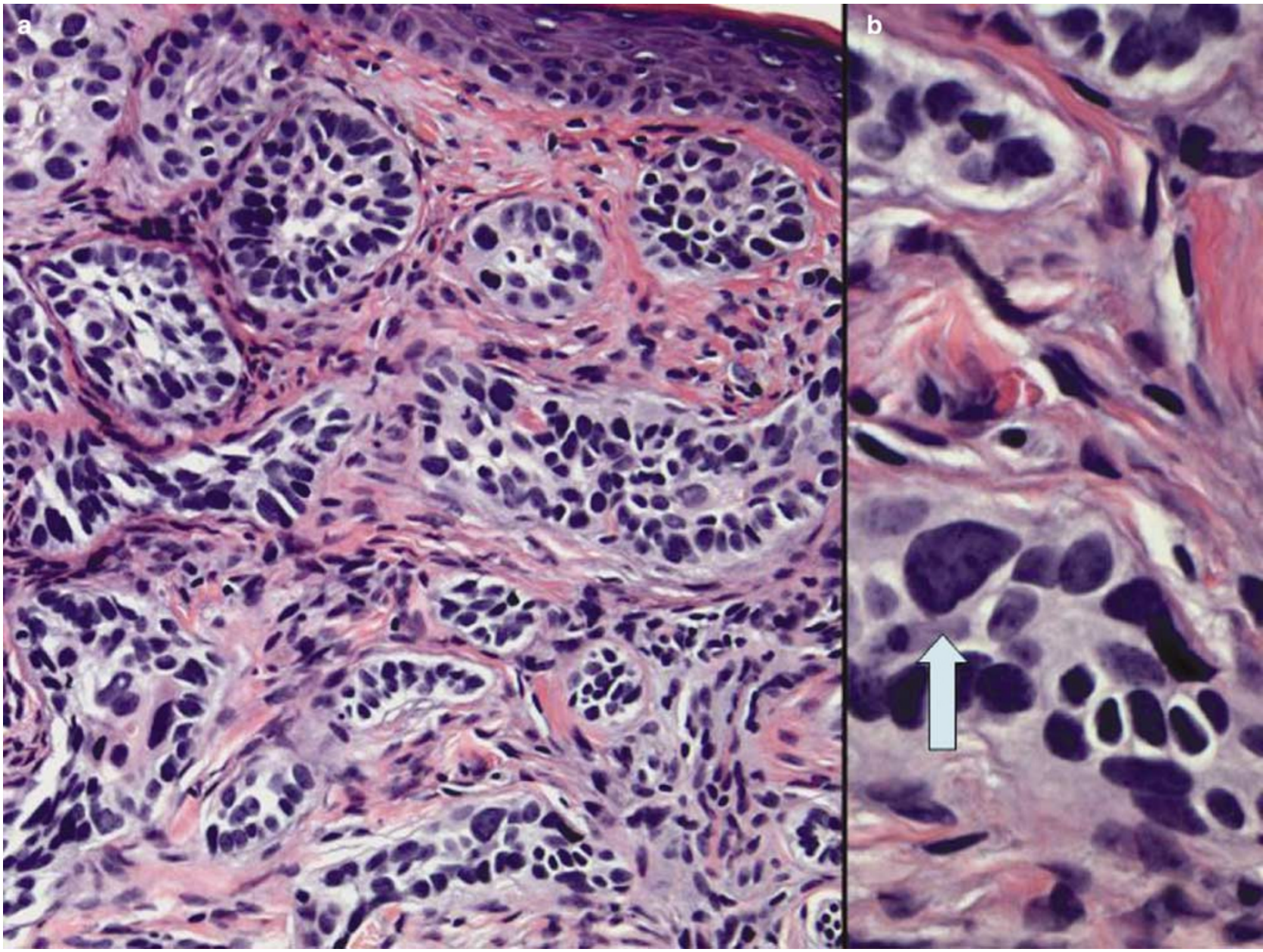

Figure 13 Pleomorphic BCC: histomorphology. In pleomorphic BCC, the tumor nests have a similar architectural pattern to nodular or mixed nodular and infiltrative growth BCC (a). However, the tumors at high-power microscopy show pleomorphic nuclei with large diameters ('monster cells') (arrow) (b).

patients with nevoid BCC syndrome of Gorlin and Goltz (Figure 3).

\section{Follicular BCC}

On occasion, a BCC will show matrical differentiation whereby shadow cells adjacent to islands of proliferating basaloid cells are present and so mimic a pilomatricoma. ${ }^{44-47}$ The shadow cells have an anucleate morphology and eosinophilic cytoplasms often accompanied by zones of calcification. ${ }^{45}$ Mitoses, apoptic cells and high-grade nuclear atypia are absent. ${ }^{44}$ The term 'follicular squamous cell carcinoma' has been used to describe squamous cell carcinoma arising in the wall of an epidermal cyst; BCC arising in this setting is a rare event but is not unique to our experience (personal observation).

\section{Pleomorphic BCC}

Some BCCs, particularly of nodular architecture, show strikingly enlarged giant hyperchromatic nuclei with amorphous nucleoplasms. These are termed pleomorphic BCC or 'basal cell epithelioma with monster cells'. ${ }^{48}$ Typically, these mis-shapen giant nuclei are either scattered individually through tumor lobules or show clustering suggesting that they are components of a similar clone (Figure 13). All cases evaluated by static image analysis cytometry have proven to be aneuploid ${ }^{49}$ but paradoxically, mitoses, although present with roughly the same frequency as seen in typical nodular BCCs, are not often atypical. ${ }^{48,49}$ As these pleomorphic monster cells impart no prognostic significance from the standpoint of enhanced biological aggressiveness, we speculate that this represents a form of senescent atypia.

\section{$B C C$ with sweat duct differentiation}

Typically seen in nodular BCC in some $1 \%$ of cases in our experience is otherwise typical eccrine, and sometimes apocrine, differentiation ${ }^{50,51}$ whereby tubules lined by the cuboidal epithelium with an internal eosinophilic cuticle are centrally disposed in otherwise typical basaloid tumor cell aggregates. The internal eosinophilic cuticle decorates with immunohistochemical stains for carcinoembryonic antigen and epithelial membrane antigen (EMA).42,50 


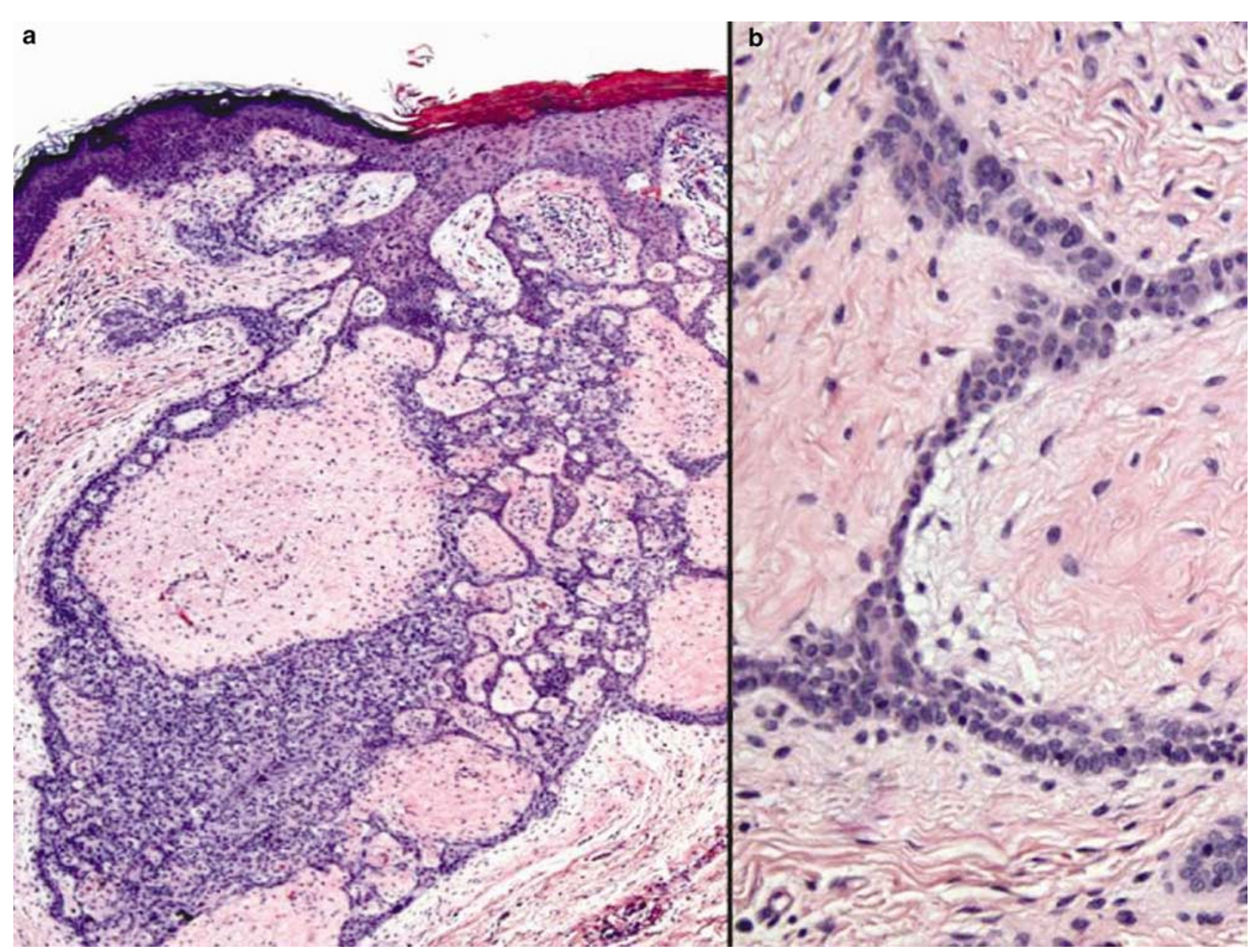

Figure 14 Fibroepithelioma of Pinkus: histomorphology. The fibroepithelioma of Pinkus manifests atypical basaloid cells that grow in thin lacy strands radiating down from points of continuity with the overlying epidermis (a). The stroma is often myxoid or shows plump stromal cells with collagen deposited around the basaloid tumor tongues (b).

\section{BCC with sebaceous differentiation}

The BCC with sebaceous differentiation is differentiated from sebaceous adenoma by having a germinative cell component which occupies greater than $50 \%$ of the transverse diameter of tumor lobules that typically manifest a rounded morphology with areas of slit-like retraction accompanied by mitoses and apoptotic debris. Unlike sebaceous carcinoma, there is no pagetoid spread in the overlying epidermis, no haphazard infiltrative growth morphology, no desmoplastic stromal reaction and no invasion of adjacent structures. Sebaceous adenoma, in contrast, is characterized by a lining of germinative cells less than $50 \%$ of the diameter of the neoplastic lobule while sebaceous hyperplasia typically has a peripherally disposed layer of germinative cells 1-2 cells thick. In contrast is the sebaceoma, a tumor that manifests a haphazard array of germinative epithelium admixed with sebocytes and structures that recapitulate sebaceous ducts. Particularly problematic are the sebaceous neoplasms of Muir-Torre syndrome, which sometimes defy precise classification by the foregoing scheme. ${ }^{52}$

\section{Fibroepithelioma of Pinkus}

Described by Pinkus ${ }^{53}$ in 1953 the fibroepithelioma typically arises above the natal cleft or on the lower trunk as a pink or flesh colored nodule with a constricted inferior margin suggesting a seborrheic keratosis. ${ }^{55}$ In this tumor, elongated basaloid epithelial strands manifesting slit-like retraction from stroma are enmeshed in a myxoid matrix or a background of proliferating spindle cells with abundant collagen (Figure 14). If a lesion is completely excised, a well-demarcated, pushing inferior and lateral margin is noted; the tumor frequently connects to the overlying epidermis at multiple points. A cystic variant is described. ${ }^{55}$ The important differential diagnostic consideration is the eccrine syringofibroadenoma of Mascaro, characterized by a typical acral disposition and comprising elongated basaloid strands containing central eccrine ductal cells and a well defined cuticle; these connect to the undersurface of the overlying epidermis in the fashion of eccrine straight ducts. Deeper levels through the paraffin block will show the basaloid strands of the eccrine syringofibroadenoma 
to have a central eccrine ductal differentiation and cuticle, unlike the solid undifferentiated basaloid epithelial columns of fibroepithelioma. ${ }^{56}$ Some observers regard the fibroepithelioma as a form of 'fenestrated' trichoblastoma, a lesion held to be a benign analogue of BCC that shares many morphological features of BCC but has not to date been shown to manifest PTCH mutations and dominantly affects sun-protected skin. ${ }^{57}$

\section{Recurrent BCC}

In approximately $10 \%$ of BCCs treated by conventional management, either surgical excision or curettage followed by fulguration of the lesional base, recurrent tumors appear at some future point (Figure 15). ${ }^{2,3}$ The recurrence rate reflects margin positivity after attempted surgical excision and varies by histologic type, being highest for the aggressive growth variants (for example $26.5 \%$ for infiltrative BCCs) and lowest in the indolent growth variants (eg 6.4 and $3.6 \%$ for nodular and superficial BCC, respectively). ${ }^{32}$ Following Mohs micrographic surgery, the recurrence rate is said to be in the $1 \%$ range. $^{2,3}$ The recurrence rates may also differ based upon the anatomic site, particularly as regards lesions of the nose and ears, ${ }^{2,3,20}$ where higher recurrence rates may reflect peculiarities of the anatomy or a natural hesitancy on the part of clinicians to perform mutilating surgical procedures in these locations. While most recurrences are seen within 3 years following the original operative procedure, some $20 \%$ of recurrences manifest themselves between 6 and 10 years after the original surgery. ${ }^{20}$ Any subsequently managed recurrent lesion has a further enhanced risk of recurrence

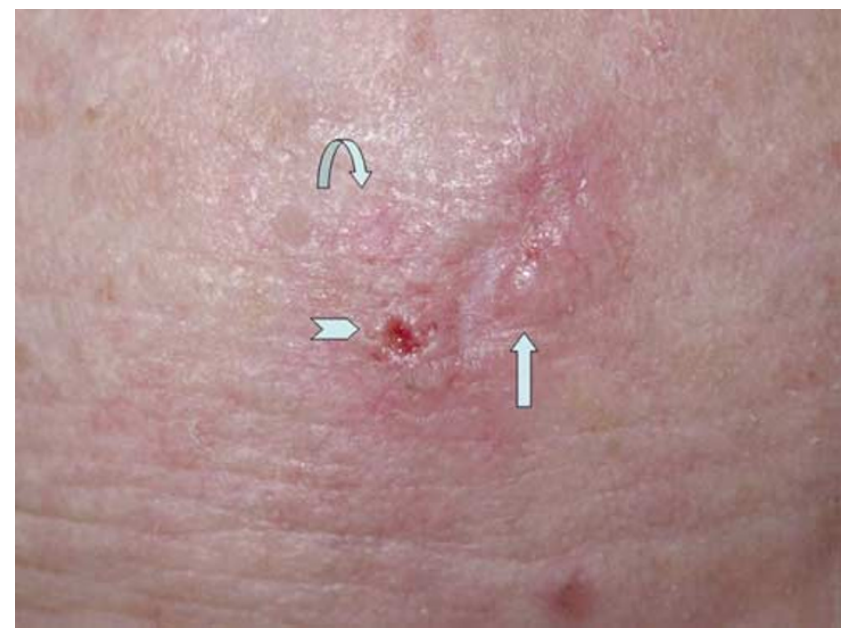

Figure 15 Recurrent BCC: clinical morphology. In this tumor, a scariform plaque is present at the site of a previous biopsy. There is a rolled edge along one side of the tumor representing a nodular growth component (straight arrow) while the infiltrative growth component is recognizable only by pink discoloration of the skin (curved arrow) and has a poorly demarcated border. The arrowhead marks a recent biopsy site. (Case courtesy of Dr Michael Wilkerson, Tulsa, OK.) said to be in the $40 \%$ range. ${ }^{15}$ This, too, reflects the difficult anatomical locations and the disruption of pre-existing architecture by scarring. ${ }^{8}$ Recurrent BCC is characterized clinically by areas of induration, erythema, ulceration or bleeding at a prior operative site for known BCC (Figure 16). The histomorphology of recurrent BCC reflects, therefore, the character of the neoplasm which is more often an aggressive growth than indolent growth variant, ${ }^{2,3,32,58}$ the presence of scar formation that disrupts the pre-existing native anatomy, and the depth of infiltration, whereby recurrent lesions tend to have, at least in so far as the aggressive growth variants are concerned, no connection to the overlying epidermis or to pre-existing follicular structures (Figure 16). There is an apparent correlation between the measured distance of the tumor to the nearest lesional edge and the recurrence rate. ${ }^{6}$

\section{Pathogenesis}

\section{Introduction}

BCC is held to derive from basaloid epithelia located in the follicular bulges, in the anagen hair bulbs and the follicular matrix cells, and in specific basaloid cells of the interfollicular epidermis. ${ }^{7,8,37,59}$ The cells of origin are held to be pluripotent progenitor epithelia in adults or epithelial germ cells in the case of those neoplasms arising in childhood (ie linear basal cell nevi). BCCs manifest a keratin profile similar to that of the lower part of the hair follicle $^{60}$ and that is therefore distinct from that of the adjacent epidermal basal layer epithelia. ${ }^{60} \mathrm{In}$ particular, and held to reflect their derivation from basaloid epithelia, BCCs express keratins type $5,6^{61}$ and $14^{62}$ and also alpha 2 and beta 1 integrins $^{63}$ in a fashion that does not correlate well to tumor subtype. The expression of CD10 supports deriva-

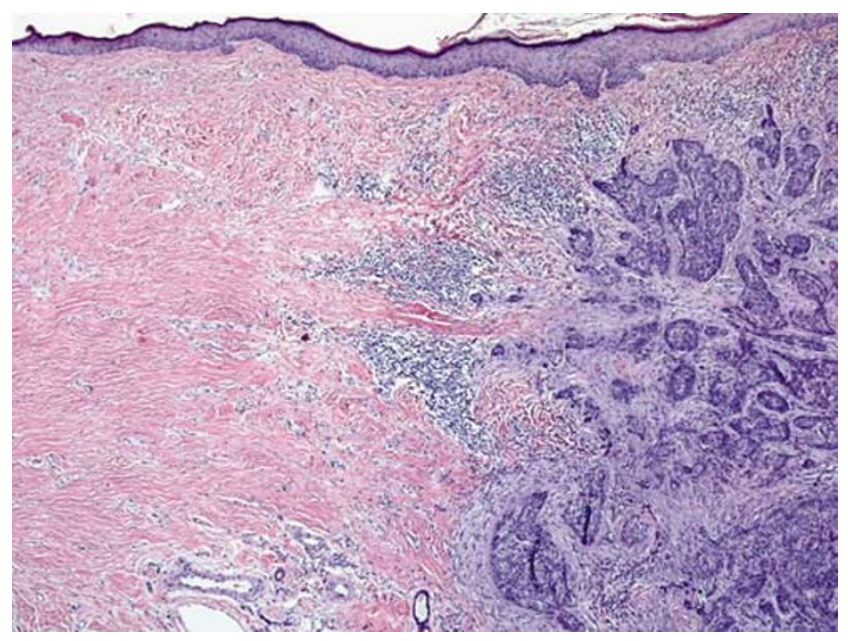

Figure 16 Recurrent BCC: histomorphology. In the same lesion illustrated in Figure 15, a biopsy showed a mature fibrous scar in continuity with areas of recurrent BCC of mixed nodular and infiltrative growth types. 
tion from the folliculo-sebaceous unit. ${ }^{64} \mathrm{Key}$ to our understanding of the pathogenesis of BCC has been the unraveling of the molecular basis of the nevoid BCC syndrome.

\section{Nevoid BCC}

The nevoid BCC syndrome or Gorlin-Goltz syndrome $^{23,24}$ is inherited as an autosomal dominant trait with a minority of cases representing sporadic mutations. ${ }^{23,24}$ Typically expressed in young adulthood, the syndrome comprises multiple basal cell cancers and other anomalies as described below. It is now recognized that for most patients the abnormality represents a mutation in the human homologue of the PTCH. ${ }^{25}$ A tumor suppressor gene, PTCH is sited on chromosome 9 q22-q31. ${ }^{26}$ The PTCH gene product functions as a transmembrane receptor for the Sonic hedgehog (shh) protein; when binding of the wild-type protein occurs, the inhibition by PTCH of a second seven-span transmembrane protein termed Smoothened (smo) is downregulated. The inhibition of smo is held to be relieved by mutations of PTCH or SMO that eventuate in cell proliferation (Figure 17); ${ }^{65}$ PTCH gene mutations produce truncated proteins incapable of binding to and inactivating smo. ${ }^{66}$ Perturbations of the SHH pathway can occur through mutations or deletions of PTCH, SMO and presumably of the zinc-finger glioma transcription factor (Gli)-1 that is normally expressed in the human hair follicle. ${ }^{67}$ Upregulation of Gli proteins (Figures 18 and 19) has been shown by quantitative reverse transcriptase polymerase chain reaction assay in BCC $^{68,69}$ and may play an important role in the initiation of BCC through

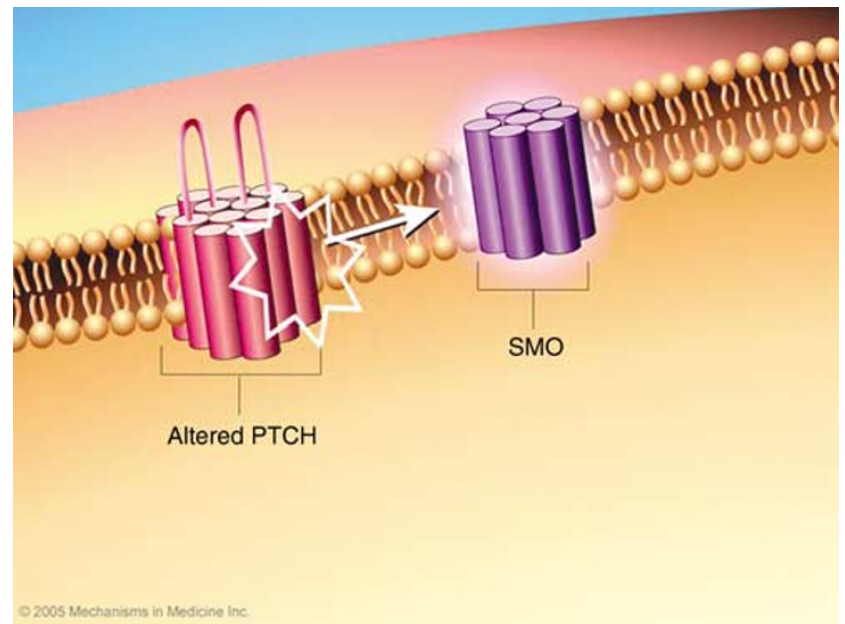

Figure 17 The PTCH gene product resides in the phospholipid bilayer of the plasma membrane. Its normal function is to bind smoothened (smo), which is released after binding of the sonic hedgehog (shh) signaling protein. Mutations that cause truncation of the ptch protein result in a situation where smo expression is constitutively upregulated in the absence of the binding of shh protein. the activation of the BCL2 gene (Figure 20). ${ }^{70}$ Gli proteins are also downstream regulators of the $\mathrm{SHH}$ signaling pathway, leading to increased tRNA expression through the basonuclin gene system ${ }^{71}$ and possibly as well through the forkhead/wingedhelix domain transcription factor $\mathrm{FOXE}-1 .{ }^{72} \mathrm{In}-$ creased FOXM-1 levels, upregulated through shh signalling via Gli1, may be specific for sporadic BCC. ${ }^{73}$ Gli2 is able to induced G1-S phase progression in contact-inhibited keratinocytes, apparently through the transcription factor E2F1. ${ }^{74}$ Antagonists of the shh/smo signaling pathway such as the steroidal alkaloid cyclopamine can selectively

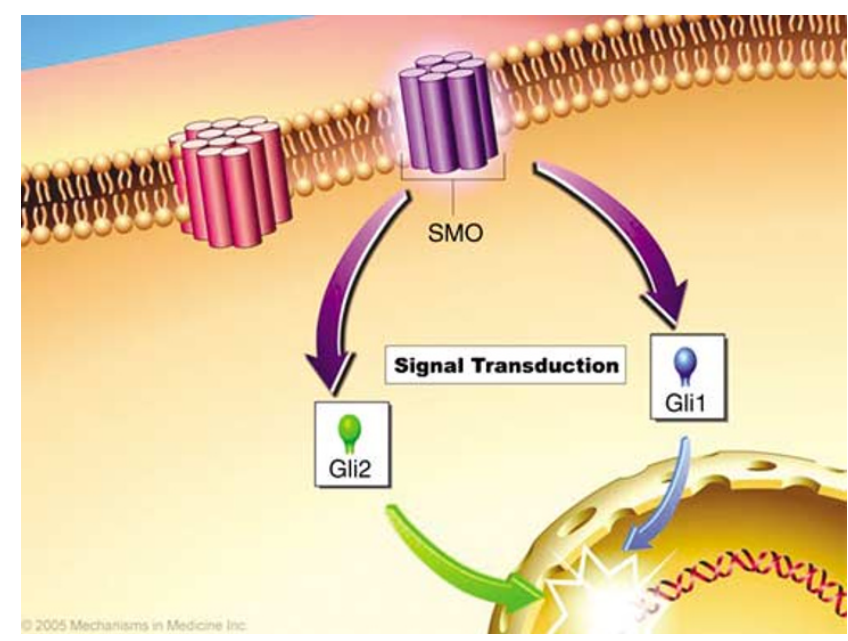

Figure 18 The smo protein, when unbound by ptch, acts as a signal transducer upregulating the expression of glioblastoma (Gli)-1 and Gli-2 signalling proteins.

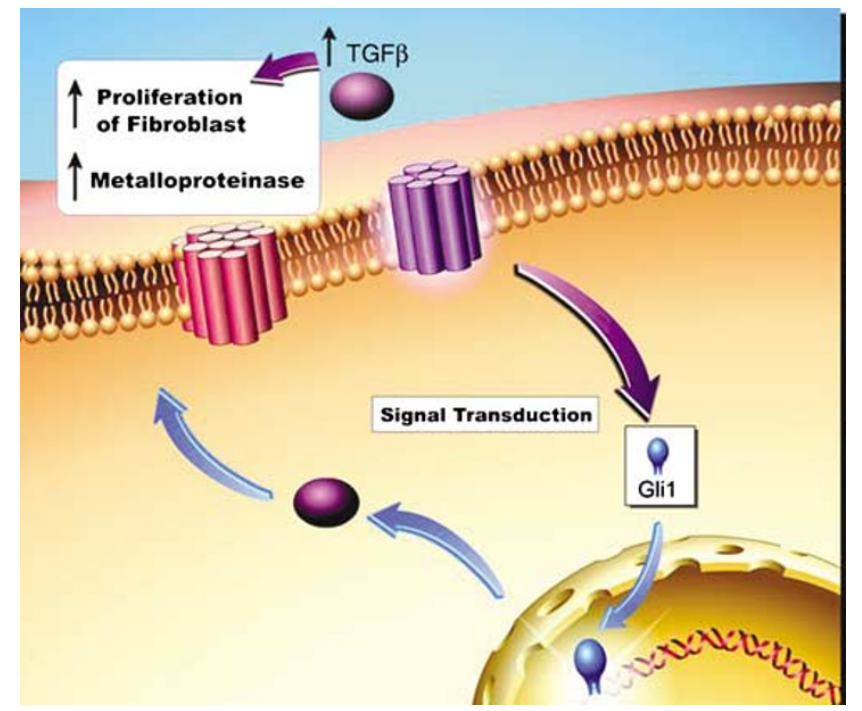

Figure 19 The Gli-1 protein binds to DNA to cause upregulation of the expression of transforming growth factor- $\beta$ (TGF- $\beta$ ). TGF- $\beta$ then migrates through holes in the nuclear envelope into the extracellular space to cause proliferation of fibroblasts and upregulated expression of metalloproteinases by them that cause dissolution of basement membrane material. 


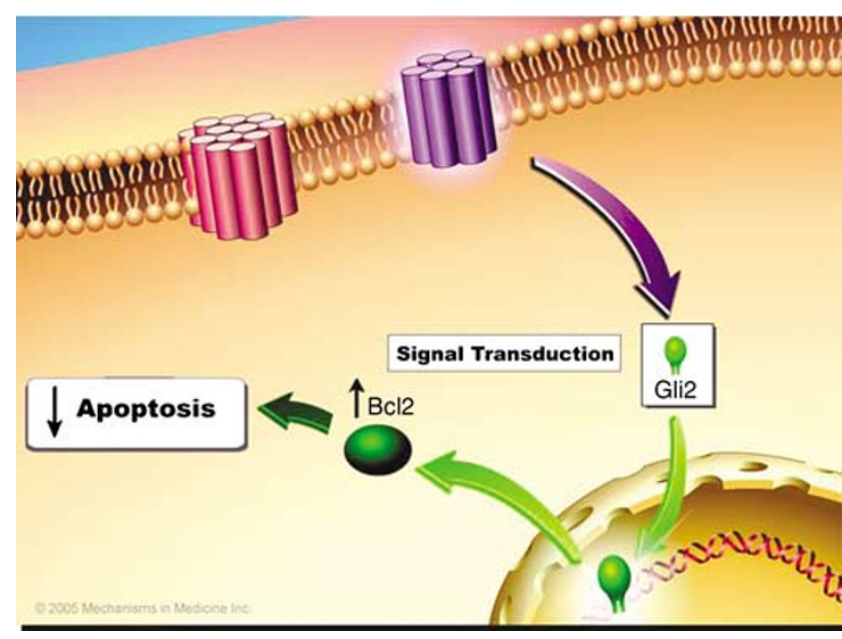

Figure 20 The Gli-2 protein product binds to chromosome 18 to cause upregulated expression of bcl-2 protein. The bcl-2 protein is believed to then migrate through the nuclear envelope. Its function along the internal cristae of the mitochondria appears to impact oxygen consumption and ATP utilization. Bcl-2 is an antiapoptotic protein that helps to increase cell longevity. Normally functional in the operation of the hair follicle in a fashion that appears to prevent conversion from anagen through to the catagen phase of the hair cycle, bcl-2 may be the common pathway where those sporadic BCCs not impacted by PTCH mutations acquire similar properties to those neoplasms seen in basal cell nevus syndrome and in the setting of those sporadic mutations that impact the ptch/smo system.

induce differentiation and apotosis of tumor cells in vivo and may emerge as a potential therapeutic modality in the future. ${ }^{75}$

\section{Sporadic BCC}

Perturbation of the SHH pathway, which is the rule in heredofamilial BCC, appears to be frequently operative in the sporadic BCC as well. Mutations of SMOH or PTCH were detected in 12 of 31 sporadic BCCs in one study $;^{76}$ the same group of researchers showed mutations in this pathway in two-thirds of sporadic BCCs in a subsequent study. ${ }^{77}$ An additional or alternate pathway of tumorigenesis appears to be at play in the remainder.

The expression of bcl-2, an inner mitochondrial membrane protein that inhibits apoptosis, has been demonstrated in BCCs of sporadic type. By semiquantitative analysis, preferential overexpression of bcl-2 has been shown in the indolent-growth forms of BCC (ie superficial and nodular BCC). ${ }^{7}$ In our proposed scheme, immortalization of progenitor epithelia of the hair follicle and the interfollicular epidermis by bcl-2 predisposes to subsequent mutagenic 'hits' from UV light. In particular, enhanced expression of p53 occurs in the absence of concomitant up regulation of p21 expression, suggesting that mutagenesis of p53 appears preferentially in the aggressive growth vs the indolent growth variants of BCC (Figure 21) ${ }^{38,78}$ Most of the

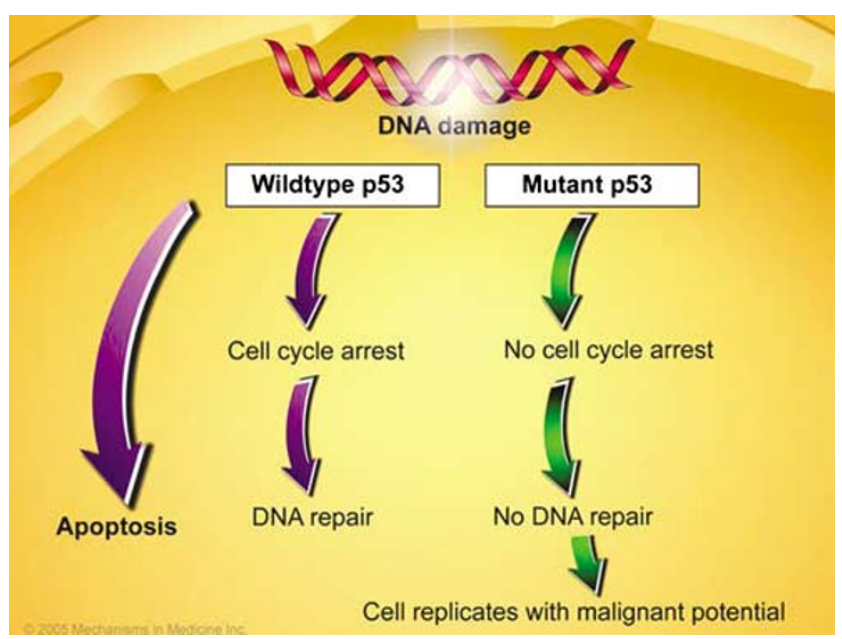

Figure 21 UV light-induced damage causes conversion from wild-type to mutant p53. Wild-type p53 causes cell cycle arrest through the p21/retinoblastoma gene product pathway in order to enable the repair of DNA in cells subjected to sublethal genotoxic injury. It also promotes apoptosis of irreparably damaged cells through the bcl2/bax system. Mutant p53, in contrast, does not effect cell cycle arrest. In consequence, DNA repair does not take place and cells are not driven down the apoptotic pathway, enabling them to then replicate and to acquire further genomic instabilities leading to an enhanced malignant potential.

tumor suppressor genes are protein tyrosine kinases; the mode of action of these enzymes as they impact cell cycle activity results in alterations of tissue phosphate levels detectable by near infra-red (NIR) spectroscopy. ${ }^{79-81}$ By noninvasive methods, in-vivo NIR spectroscopy can be used to map the extent of BCCs and also to distinguish them from other cutaneous tumors with a high degree of accuracy. ${ }^{79-83}$

That the two proposed mechanisms of tumorigenesis are complementary is suggested by the fact that shh-expressing cells also manifest increased expression of bcl- $2,{ }^{84}$ likely through activation of the Gli proteins that are expressed in the outer root sheath of the normal hair follicle and in BCCs; ${ }^{65}$ Gli-2 in particular appears to play an important role in the activation of the BCL2 gene. ${ }^{70}$

\section{UV Light-Induced Mutagenesis and Biologic Transformation}

BCCs express p53 protein and do so in a preferential fashion in aggressive growth variants. ${ }^{78,85,86}$ Mutations of p53 have been documented in up to $40 \%$ of studied BCCs $;{ }^{77} 72 \%$ of the mutations bear the signature of UV light induction. The aggressive growth variants of sporadic BCC are associated with stromal fibroplasia and overexpression of what is likely mutant p53. ${ }^{38,78}$ It is this stromal response to tumor which makes the aggressive growth BCC less amenable to local therapy and control. ${ }^{32}$ The interaction between tumor and stroma, as demonstrated in many neoplastic systems, is critical to lesional pathogenesis. Loss of basement membrane material 
around individual tumor cell nests occurs with progression from indolent to aggressive growth neoplasms. ${ }^{36}$ The working hypothesis is that activation of matrix metalloproteinases in the process of transformation results in the digestion of basal lamina around tumor nests, promoting the elaboration and/or release of proplastic cytokines and their subsequent availability to the rapidly proliferating aggressive growth neoplasms. Perhaps corroborating this hypothesis is the fact that the aggressive growth BCCs have been shown to selectively express syndecan-1 in the adjacent stroma, but not in the tumor cells. ${ }^{87}$ Syndecan-1 is a member of the syndecan glycoprotein family, held to play an important role in inhibiting tumor growth and invasion through its role as a receptor for growth factors in the extracellular matrix.

In our hands, the indolent growth variants are found widely distributed on both sun-exposed and sun-protected skin, while the aggressive growth variants such as infiltrative and morpheaform BCC are more frequent in sun-exposed skin. ${ }^{7}$ Australian observers have confirmed these findings in a large series using conventional histology. ${ }^{88}$ Men and women are affected in roughly equal proportions with the majority of tumors occurring in the head and neck region. ${ }^{2,3,20}$ In our experience, male subjects tend to manifest more frequent localization to the left side of the face, which may reflect the fact that they were driving vehicles in North America prior to the advent of sun screens. Roughly onequarter of cases occur on the nose, the most frequently involved site. ${ }^{2-6}$ Less prevalent overall in more darkly pigmented races, the histologic types of BCC seen in Africans and Hispanics have a similar histomorphology. ${ }^{89}$

\section{Other Risk Factors for Sporadic BCC}

The incidence of BCC is much more common in individuals who have received a solid organ transplant ${ }^{90,91}$ in whom herpes virus like DNA sequences have been demonstrated ${ }^{90,91}$ and in whom tumors appear to have an increased tendency for recurrence and metastasis. ${ }^{92}$ In concert with this more aggressive behavior, the histologic types are different in patients with immune suppression in whom infiltrative growth BCC is more common than nodular and/or superficial variants. ${ }^{12}$ In contrast, superficial BCC predominates in individuals with renal failure, diabetes mellitus and human immunodeficiency virus infection. ${ }^{12}$

\section{Host Response to Neoplasm and Tumor-Stromal Interactions}

Most inflammatory cells in the stroma of a BCC are lymphocytes of T-helper phenotype, ${ }^{93}$ while T-cytotoxic/suppressor cells and B lymphocytes are uncommon ${ }^{8}$ and plasma cells, when present, are generally held to reflect coexisting ulceration. Patients with immune suppression have reduced numbers of T lymphocytes around their tumor nests and tongues. Histiocytes are often present in significant numbers, most expressing HLA-DR antigens $^{8,80}$ and some representing Langerhans' cells. ${ }^{8}$ The apposition of HLA DR-expressing lymphocytes appears to be associated with upregulation of HLA DR antigens on the surface of some tumor cells. ${ }^{93}$ Mast cells are often present in increased numbers around the periphery of tumor islands ${ }^{8,94}$ and may play a role, through release of their cytosolic products, in provocation of fibrosis around the tumor tongues of aggressive growth neoplasms. An amyloid-like substance held to derive from degenerating epithelia is present in and around some indolent growth BCCs ${ }^{95,96}$ but mucin deposition is a far more common finding. The mesenchymal mucins, likely products of stromal cells, represent hyaluronic acid and dermatan sulfate. ${ }^{95,96}$ Cylinder-like inclusions of hyalin material resembling those seen in the cylindroma are demonstrated in some nests of nodular $\mathrm{BCCs}^{97}$ and appear to comprise intermediate filaments including vimentin, keratin and myosin. ${ }^{97}$ In rare cases, needleshaped fibers comprising collagenous crystalloids are identified ${ }^{98}$ and contain types I and III collagen, held to reflect degeneration of extracellular matrix components.

Ultrastructural examination gives some clues to the pathogenesis and transformation characteristics of BCC. Both the superficial and nodular variants of BCC $^{36,99,100}$ are surrounded by a continuous basement membrane zone comprising collagens type IV and $\mathrm{V}$ admixed with laminin (Figure 22). The aggressive growth variants (ie morpheaform, metatypical and infiltrative growth subtypes) manifest an absent basement membrane (Figure 23). ${ }^{36,100}$ Although formerly held to constitute a barrier to invasion, ${ }^{99}$ in fact the basement membrane zone may first be secreted by and later dissolved by neoplastic cell systems, such as in the case of upregulated transmembrane metalloproteinase activity in vertical growth phase melanoma-derived cell lines in vitro, ${ }^{101}$ a biologic function which has specific implications. In particular, we speculate that the basement membrane material may act as a trap for proplastic cytokines derived from tumor cells, stromal cells and from inflammatory cells. These proplastic cytokines, when liberated by a transmembrane or other matrix metalloproteinase may then be bioavailable to promote tumor growth. ${ }^{101}$ In any event, the interaction between tumor and stroma plays a key role in basal cell cancer biology. The aggressive growth variants, manifesting pronounced stromal desmoplasia, are not easily treatable by simple curettage and fulguration. The clinician can with reasonable accuracy predict when he/she is dealing with an aggressive growth variant as the curette loop will strike the tumor and its fibrotic matrix to produce a 'gritty' sensation quite unlike 

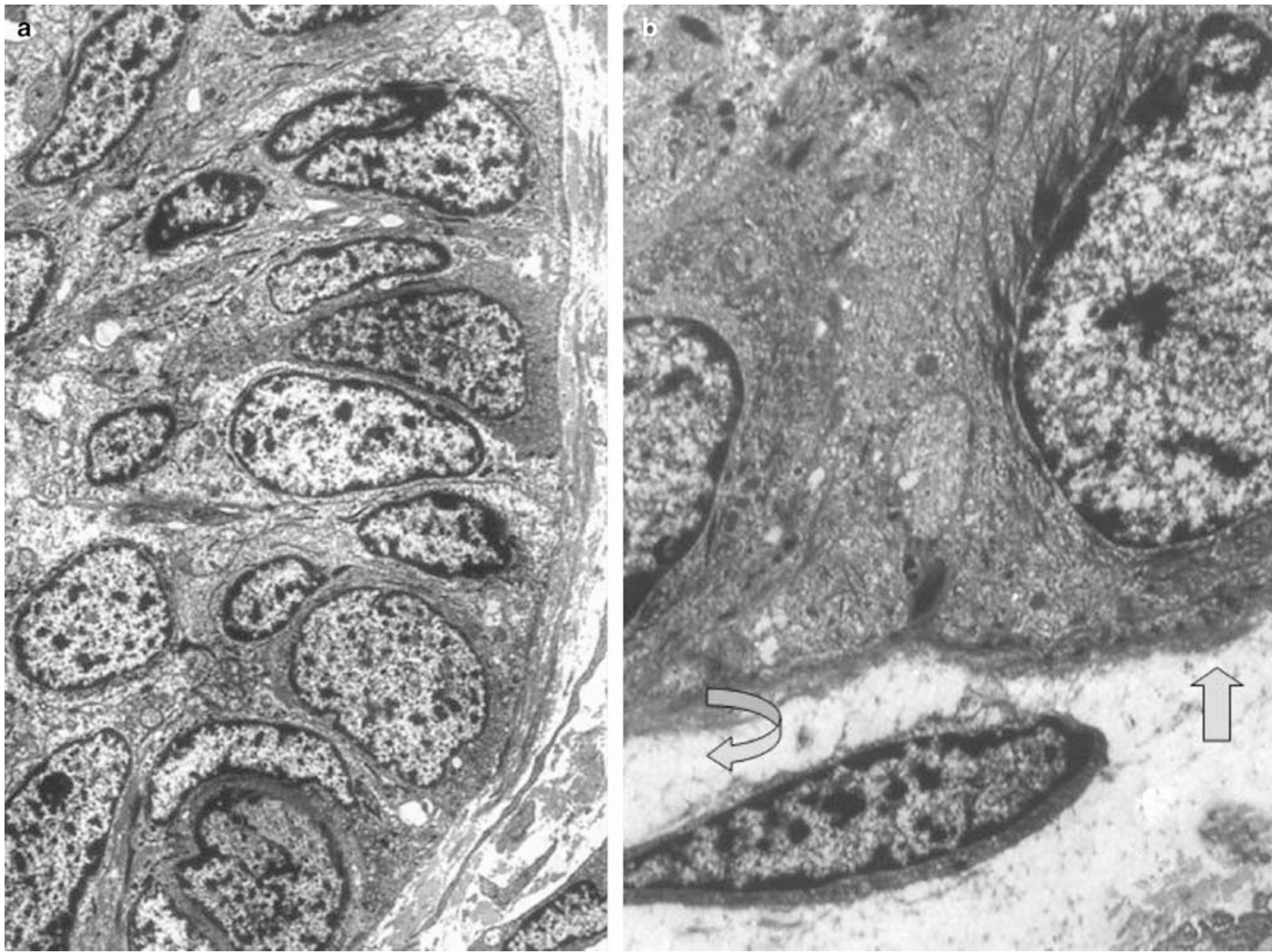

Figure 22 Nodular BCC: ultrastructural features. The nodular BCC is characterized by rounded nests of neoplastic basaloid cells (a) that are deliminated by an almost continuous basal lamina (b, straight arrow). Note the presence of numerous hemidesmosomes at the interface between the plasma membrane of the neoplastic basal cells and the adjacent delimiting basal lamina (straight arrow), and the absence of anchoring fibrils (curved arrow) that helps to explain the slit-like stromal retraction so characteristic of BCC at the light microscopic level.

the nongritty character of superficial and nodular BCCs. It is the percolation of cells through stroma and their protection from the curette loop by the desmoplastic collagen table which necessitates an alternative approach, typically a surgical one, to the aggressive growth tumors. Other ultrastructural features that find expression at the light microscopic level include the presence of hemidesmosomes along the margin of a nodular or superficial BCC in decreased numbers vs normal adjacent epidermis. This reduction in hemidesmosome concentration in concert with the absence of type VII collagen anchoring fibrils is held to be a potential explanation for the retraction spaces seen at the light microscopic level between the nodules of tumor cells and the adjacent stroma. Cytoskeletal microfilaments uncommon in normal epithelia are present in BCC, particularly in the invasive subtypes ${ }^{102}$ and could in part explain enhanced tumor mobility through stroma. Actin protein expression is upregulated in BCCs vs adjacent normal tissue via a series of specific protein kinases (unpublished data of Crowson and Garcia, 2005); differential expression of actin filaments and their attachment plaques has been implicated as a significant event in the evolution of melanoma. ${ }^{103,104}$

\section{Differential Diagnosis}

The different forms of BCC each carry with them a different set of differential diagnostic possibilities. Superficial BCC, by showing oftentimes sharply demarcated clones of basaloid cells, calls to mind Bowen's disease and sometimes other clonal proliferations such as clonal seborrheic keratosis or even intraepidermal eccrine porocarcinoma in situ. Essential to the distinction is the identification of a peripheral palisade along the base of the lesion at the dermal-epidermal junction in concert with slitlike retraction of the stroma. Eccrine cancers often have true lumenal margins or intracytoplasmic 


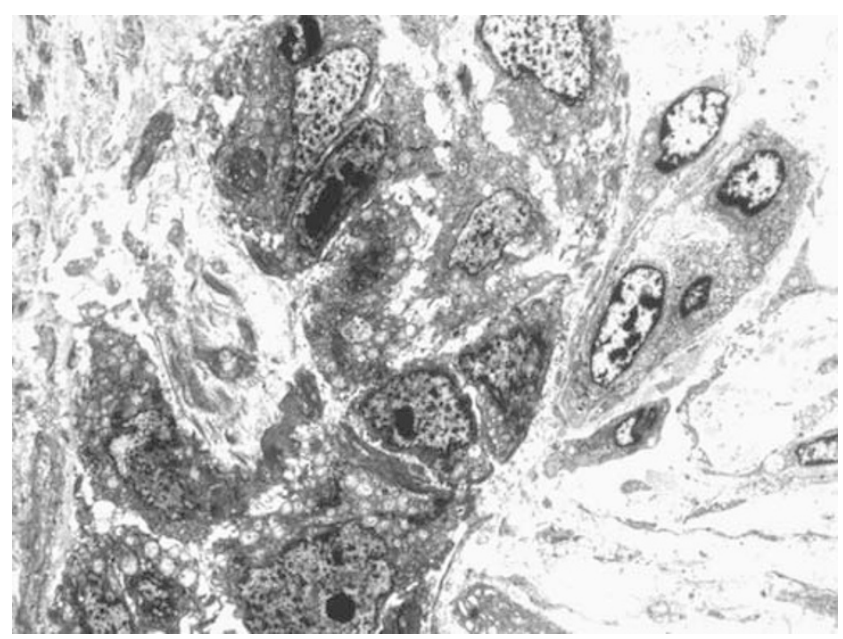

Figure 23 Infiltrative growth BCC: ultrastructural characteristics. In this infiltrative growth of BCC, the tumor tongues have irregular contours. There is no delimiting zone of basement membrane material.

lumina reflecting glandular differentiation. Bowen's disease shows pronounced intercellular bridge formation and cytoplasmic keratinization and has frequent and atypical mitotic figures that are uncommon in superficial BCC. Seborrheic keratoses can cause surprising difficulty in distinction from both superficial and early nodular BCCs but generally the seborrheic keratosis manifests a plaquelike architecture whereby a straight line drawn between the native epidermis at the shoulders of the lesion lies beneath the plane of the proliferation. Seborrheic keratoses comprise basaloid epithelia, usually without atypia or mitotic activity, accompanied by pseudohorn cyst formation and either a pigmented reticulated, a solid acanthotic or a papillomatous architecture. Actinic keratoses occasionally mimic BCCs as well. In particular, some actinic keratoses manifest downward buds of atypical basaloid cells in sun-damaged skin but these are surmounted by parakeratosis and typically lack slitlack retraction from the subjacent stroma or mucin deposition.

Nodular BCC raises consideration to a nodular intradermal eccrine proliferation such as clear cell hidradenoma or eccrine spiradenoma, the latter showing intertwined dark basaloid and lighter cuboidal lumenal cells reflecting eccrine differentiation. These neoplasms frequently have few mitoses and often do not connect to the overlying epidermis. Peripheral palisading, stroma mucinosis or individual cell necrosis are unusual in the tumor nests of benign eccrine adnexal neoplasia. The trichoepithelioma manifests abortive hair papilla formation with papillary mesenchymal bodies in basaloid nests that are in turn encompassed by a distinctive stroma populated by plump stromal cells that is sharply demarcated from the adjacent native dermis. Trichoepitheliomas manifest no mitotic activity, no individual cell necrosis and only infrequently have melanin pigment within tumor nests. Trichoepitheliomas also frequently radiate around central keratin-filled cystic structures. It is the more differentiated BCCs, such as the BCC with abortive hair papilla formation, and the infundibulocystic BCC which can cause confusion with respect to trichoepithelioma. ${ }^{105}$ Immunostains can be helpful, such as CD34 that is expressed in the stroma of trichoepitheliomas but not that of BCCs, ${ }^{44,106}$ and bcl-2, expressed diffusely in the indolent growth BCC but only around the periphery of a trichoepithelioma. ${ }^{107}$ Trichofolliculoma, on the other hand, manifests a central keratin-filled pore containing hair shaft material, from which radiate squamoid bands that in turn connect to basaloid islands recapitulating follicular differentiation. The differentiated forms of nodular BCC such as BCC with sebaceous or eccrine adnexal differentiation can be distinguished in the former instance by criteria already listed above and in the latter by the presence of slit-like retraction, individual cell necrosis and mitotic activity. As well, the eccrine components of BCC, when present, are only a minor contribution to the overall volume of tumor. We do not consider distinction of the 'adenoid' form of BCC from digital papillary adenocarcinoma and other malignant eccrine neoplasms to be a significant or realistic concern in the vast majority of cases.

Some BCCs show clear cell differentiation comprising intracytoplasmic glycogen accumulation and apparently recapitulating outer root sheath (trichilemmal) differentiation. In this setting, sebaceous carcinoma enters the differential diagnosis. Sebaceous carcinomas decorate with antibodies to low molecular weight keratins (ie CAM 5.2) and strongly with antibodies to EMA in our hands. Others describe absent EMA expression in the poorly differentiated areas of sebaceous carcinoma. ${ }^{108}$ Basal and squamous cell carcinomas express EMA only faintly and are typically negative for CAM 5.2. The Thomsen-Freidenreich (T) antigen is expressed in sebaceous neoplasms but not by most basal and squamous cell carcinomas, and has been held to be a useful diagnostic tool. ${ }^{109}$ Some authors have found the marker to be less helpful. ${ }^{110}$ Androgen receptor expression in sebaceous neoplasms, including in the seboblasts as well as the differentiated sebocytes, has been proposed as a diagnostic adjunct ${ }^{108}$ Androgen receptor expression was reported in $78 \%$ of BCCs but no trichogeneic neoplasms in one study; ${ }^{111}$ by implication the utility of this marker in differentiating sebaceous neoplasms from BCC must be considered dubious. The distinction of these clear cell tumors from sebaceous carcinoma and sebaceous epithelioma rests on the demonstration of cytoplasmic glycogen (using an alcian bluePAS and PAS-diastase staining combination) and by the expression of carcinoembryonic antigen. Recognition of sebaceous differentiation in a BCC would not alter the biologic potential of the tumor but 
sebaceous carcinomas tend to have more stubborn local aggression and also a metastatic capability which is likely more significant than for BCC. The presence of balloon cell change in a melanocytic proliferation can mimic clear cell and sebaceous differentiation in BCCs; appropriate immunohistochemical decoration with antibodies to S-100 protein, A103 (Melan A) and gp100 protein (HMB-45) makes these distinctions possible. ${ }^{112}$ Metastatic renal cell and thyroid cancers can have a clear cell morphology. The former are glycogen rich and can therefore cause diagnostic concern but typically have a highly vascular stroma associated with abundant hemorrhage. Renal cell carcinomas express CD10, CD15, AMCAR and vimentin in addition to keratins. Thyroid carcinomas decorate with antibodies to thyroid transcription factor and/or thyroglobulin (if follicular differentiation is present) enabling distinction. On occasion, a Merkel cell carcinoma comes into consideration of a solid undifferentiated form of BCC. The Merkel cell carcinoma expresses cytokeratin 20, typically as drop-like aggregates in a perinuclear disposition representing Golgi complex accentuation, in concert with neuroendocrine markers synaptophysin and chromogranin. ${ }^{113}$

With respect to the aggressive growth BCCs, the morpheaform BCC must be distinguished from other desmoplastic adnexal tumors including desmoplastic trichoepithelioma and microcystic adnexal carcinoma. Some desmoplastic trichoepitheliomas manifest an epidermal 'dell', a downward indentation of the epidermal surface, accompanied by proliferating basaloid cells, keratin cysts and only a very rare mitosis in the tumor cell population. Dermal mucin production and apoptosis are absent although calcification may be seen. In the microcystic adnexal carcinoma, a widely invasive tumor is seen which goes to all edges of a punch biopsy specimen most typically and comprises columns of vertically oriented atypical cells manifesting individual cell necrosis and mitotic activity surmounted by keratin-containing cystic structures lined by differentiated squamous epithelium. Microcystic adnexal carcinoma is a neoplasm of the mid face typically of middle-aged or elderly woman and can manifest stubborn local recurrence with disfigurement. Its correct diagnosis and appropriate extirpative surgical therapy is therefore necessary. ${ }^{114}$

\section{Conclusion}

Advances in the biology of BCC have led us to understand the pathways of lesional evolution and have induced clinicians to demand precision as well as accuracy in morphological classification. The impact upon therapy of the accurate classification of BCC is such that all practicing surgical pathologists should be aware of the histologic criteria for diagnosis and subclassification of this, the most common human cancer.

\section{Acknowledgements}

Much of the original work on basal cell carcinoma, which is described in this paper, was funded by the Misericordia General Hospital Research Foundation, Winnipeg, Canada. Funding for the illustrations of tumor biology was provided by the Arthur Curtis Foundation of the University of Oklahoma and by Pathology Laboratory Associates, Tulsa, OK. I am indebted to my colleagues Drs Thomas Hayakawa, Marshall Kadin, Cynthia Magro, Dragana Pilavdzic and Mirek Stranc who participated in the original works. The illustrations of patched and smoothened signaling were created in concert with David and Nic Searle and their colleagues at Mechanisms in Medicine, Inc., Toronto, Ontario, Canada. Expert transcription was performed by Julie Blount of Tulsa, Oklahoma.

\section{References}

1 Jacob A. Observations respecting an ulcer of peculiar character, which attacks the eyelids and other parts of the face. Dublin Hospital Rep Commun Med Surg 1827;4:232-239.

2 Miller SJ. Biology of basal cell carcinoma (Part I). J Am Acad Dermatol 1991;24:1-13.

3 Miller SJ. Biology of basal cell carcinoma (Part II). J Am Acad Dermatol 1991;24:161-175.

4 Lacour JP. Carcinogenesis of basal cell carcinomas: genetics and molecular mechansisms. Br J Dermatol 2002;146(Suppl 61):17-19.

5 Carter DM, Lin AN. Basal cell carcinoma. In: Fitzpatrick TM, Eisen AZ, Wolff K, et al (eds). Dermatology in General Medicine, 4th edn. McGraw-Hill: New York, 1993, pp 840-847.

6 Miller DL, Weinstock MA. Nonmelanoma skin cancer in the United States: incidence. J Am Acad Dermatol 1994;30:774-778.

7 Crowson AN, Magro CM, Kadin M, et al. Differential expression of bcl-2 oncogene in human basal cell carcinoma. Hum Pathol 1996;27:355-359.

8 Goldberg LH. Basal cell carcinoma. Lancet 1996;347: 663-667.

9 Price MA, Goldberg LH, Levy ML. Juvenile basal cell carcinoma. Ped Dermatol 1994;11:176-177.

10 Goldstein AM, Bale SJ, Peck GL, et al. Sun exposure and basal cell carcinoma in the nevoid basal cell carcinoma syndrome. J Am Acad Dermatol 1993;29: $34-41$.

11 Johnson TM, Tschen J, Ho C, et al. Unusual basal cell carcinomas. Cutis 1994;54:85-92.

12 Oram Y, Orengo I, Griego RD, et al. Histologic patterns of basal cell carcinoma based upon patient immunostatus. Dermatol Surg 1995;21:611-614.

13 Rao BK, Freeman RG, Poulos EG, et al. The relationship between basal cell epithelioma and seborrheic keratosis. J Dermatol Surg Oncol 1994;20:761-764.

14 Crowson AN, Magro CM. Desmoplastic trichilemmoma and its association with basal cell carcinoma. Am J Dermatopathol 1996;18:43-48.

15 Boyd AS. Tumors of the epidermis. In: Barnhill R, Crowson AN (eds). Textbook of Dermatopathology, 2nd edn. McGraw-Hill Co: New York, 2004, pp 575-634. 
16 Peschen M, Lo JS, Snow SN, et al. Linear basal cell carcinoma. Cutis 1993;51:287-289.

17 Niazi ZBM, Lamberty BGH. Perineural infiltration in basal cell carcinomas. Br J Plast Surg 1993;6:156-157.

18 Lo JS, Snow SN, Reizner GT, et al. Metastatic basal cell carcinoma: report of twelve cases with a review of the literature. J Am Acad Dermatol 1991;24:715-719.

19 Sahl WJ. Basal cell carcinoma: Influence of tumor size on mortality and morbidity. Int J Dermatol 1995;34: 319-321.

20 Randle HW. Basal cell carcinoma: identification and treatment of the high-risk patient. Dermatol Surg 1996;22:255-261.

21 Snow SN, Sahl WJ, Lo J, et al. Metastatic basal cell carcinoma: report of 5 cases. Cancer 1994;73:328-335.

22 Howell JB, Caro MR. The basal cell nevus. Arch Dermatol 1959;79:67-80.

23 Bale AE, Gailani MR, Leffell DJ. Nevoid basal cell carcinoma syndrome. J Invest Dermatol 1994;103: 126S-130S.

24 Gorlin RJ. Nevoid basal cell carcinoma syndrome. Dermatol Clin N Am 1995;13:113-125.

25 Nagao K, Fujii K, Yamada M, et al. Identification of a novel polymorphism involving a CGG repeat in the PTCH gene and a genome-wide screening of CGG-containing genes. J Hum Genet 2004;49: 97-101.

26 Kim MY, Park HJ, Baek SC, et al. Mutations of the p53 and PTCH gene in basal cell carcinomas: UV mutation signature and strand bias. J Dermatol Sci 2002;29:1-9.

27 Bale AE. The nevoid basal cell carcinoma syndrome: genetics and mechanisms of carcinogenesis. Cancer Invest 1997;15:180-186.

28 Barr RJ, Headley JL, Jensen JL, et al. Cutaneous keratocysts of nevoid basal cell carcinoma syndrome. J Am Acad Dermatol 1986;14:572-576.

29 Howell JB, Mehregan AH. Pursuit of the pits in nevoid basal cell carcinoma syndrome. Arch Dermatol 1970;102:586-597.

30 Pratt MD, Jackson R. Nevoid basal cell carcinoma syndrome. J Am Acad Dermatol 1987;16:964-970.

31 Russell EB, Carrington PR, Smoller BR. Basal cell carcinoma: a comparison of shave biopsy versus punch biopsy techniques in subtype diagnosis. J Am Acad Dermatol 1999;41:69-71.

32 Sexton M, Jones DB, Maloney ME. Histologic pattern analysis of basal cell carcinoma. J Am Acad Dermatol 1990;23:1118-1126.

33 Ackerman AB, Jacobson M, Vitale P. Clues to Diagnosis in Dermatopathology. ASCP Press: Chicago, 1991, pp 245-248.

34 Hendrix JD, Parlette HL. Micronodular basal cell carcinoma: a deceptive histologic subtype with frequent clinically undetected tumor extension. Arch Dermatol 1996;132:295-298.

35 Boyd AS, Rapini RP. Cutaneous collision tumors. Am J Dermatopathol 1994;16:253-257.

36 Hayakawa TJ, Pilavdzic D, Magro CM, et al. The ultrastructure of aggressive-versus indolentgrowth basal cell carcinoma: a comparative study (Abstract). Lab Invest 1998;78:50A.

37 Siegle RJ, MacMillan J, Pollack SV. Infiltrative basal cell carcinoma: a nonsclerosing subtype. J Dermatol Surg Oncol 1986;12:830-836.

38 Crowson AN, Magro CM, Pilavdzic D, et al. Differential stromal p53 expression in human basal cell carcinoma (Abstract). Lab Invest 1997;76:43A.
39 de Faria JL. Basal cell carcinoma of the skin with areas of squamous cell carcinoma: a basosquamous cell carcinoma. J Clin Pathol 1985;38: 1273-1277.

40 Wick MR. Malignant tumors of the epidermis. In: Farmer ER, Hood AF (eds). Pathology of the Skin, 2nd edn. McGraw-Hill: New York, 2000, pp 969-1006.

41 Lever WF, Shamberg-Lever G. Histopathology of the Skin, 7th edn. Lippincott: Philadelphia, 1989.

42 Kato N, Ueno H. Infundibulocystic basal cell carcinoma. Am J Dermatopathol 1993;15:265-267.

43 Walsh N, Ackerman AB. Infundibulocystic basal cell carcinoma: a newly described variant. Mod Pathol 1990;3:599-608.

44 Aloi FG, Molinero A, Pippione M. Basal cell carcinoma with matrical differentiation. Am J Dermatopathol 1988;10:509-513.

45 Ambrojo P, Aguilar A, Simon P, et al. Basal cell carcinoma with matrical differentiation. Am J Dermatopathol 1992;14:293-297.

46 Haskel HD, Maynes HA, McKee PH, et al. Basal cell carcinoma with matrical differentiation: a case study with analysis of beta-catenin. J Cutan Pathol 2005;32: 245-250.

47 Ali F, Brown A, Gottwald L, et al. Basal cell carcinoma with matrical differentiation in a transplant patient: A case report and review of the literature. J Cutan Pathol 2005;32:445-448.

48 Elston DM, Bergfeld WF, Petroff N. Basal cell carcinoma with monster cells. J Cutan Pathol 1993; 20:70-73.

49 Garcia JA, Cohen PR, Herzberg AJ, et al. Pleomorphic basal cell carcinoma. J Am Acad Dermatol 1995;32: 740-746.

50 Hanke CW, Temofeew RK. Basal cell carcinoma with eccrine differentiation (eccrine epithelioma). J Dermatol Surg Oncol 1986;12:820-824.

51 Misago N, Satoh T, Narisawa Y. Basal cell carcinoma with ductal and glandular differentiation: a clinicopathological and immunohistochemical study of 10 cases. Eur J Dermatol 2004;14:383-387.

52 Misago N, Mihara I, Ansai S-I, et al. Sebaceoma and related neoplasms with sebaceous differentiation. Am J Dermatopathol 2002;24:294-304.

53 Pinkus H. Premalignant fibroepithelial tumors of the skin. Arch Dermatol 1953;67:598-603.

54 Suster S, Cajal SR. Myoepithelial differentiation in basal cell carcinoma. Am J Dermatopathol 1991;13: 350-357.

55 Jones CC, Ansari SJ, Tschen JA. Cystic fibroepithelioma of Pinkus. J Cutan Pathol 1991;18:220-222.

56 Spoonemore K, Crowson AN. Eccrine syringofibroadenoma in a patient with chronic graft-versus-host disease (Abstract). J Cutan Pathol 2004;1:128-129.

57 Bowen AR, LeBoit PE. Fibroepithelioma of Pinkus is a fenestrated trichoblastoma. Am J Dermatopathol 2005;27:149-154.

58 Lang PG, Maize JC. Histologic evolution of recurrent basal cell carcinoma and treatment implications. J Am Acad Dermatol 1986;14:186-196.

59 Kore-eda S, Horiguchi Y, Ueda M, et al. Basal cell carcinoma cells resemble follicular matrix cells rather than follicular bulge cells: Immunohistochemical and ultrastructural studies. Am J Dermatopathol 1998;20: 362-369.

60 Shimizu N, Ito M, Tazawa $\mathrm{T}$, et al. Immunohistochemical study on keratin expression in certain 
cutaneous epithelial neoplasms. Am J Dermatopathol 1989;11:534-540.

61 Plumb SJ, Argenyi ZB, Stone MS, et al. Cytokeratin $5 / 6$ immunostaining in cutaneous adnexal neoplasms and metastatic adenocarcinoma. Am J Dermatopathol 2004;26:447-451.

62 Bigelow RL, Jen EY, Delehedde M, et al. Sonic hedgehog induces epidermal growth factor dependent matrix infiltration in HaCaT keratinocytes. J Invest Dermatol 2005;124:457-465.

63 Pentel M, Helm KF, Maloney MM. Cell surface molecules in basal cell carcinomas. Dermatol Surg 1995;21:858-861.

64 Yada K, Kashima K, Daa T, et al. Expression of CD10 in basal cell carcinoma. Am J Dermatopathol 2004;26: $463-471$.

65 Xie J, Murone M, Luoh SM, et al. Activating Smoothened mutations in sporadic basal-cell carcinoma. Nature 1998;391:90-92.

66 Barnes EA, Heidtman KJ, Donoghue DJ. Constitutive activation of the shh-ptc1 pathway by a patched1 mutation identified in BCC. Oncogene 2005;24: 902-915.

67 Dahmane N, Lee J, Robins P, et al. Activation of the transcription factor Gli1 and the Sonic hedgehog signaling pathway in skin tumours. Nature 1997;389: 876-881.

68 Tojo M, Kiyosawa H, Iwatsuki K, et al. Expression of the GLI2 oncogene and its isoforms in human basal cell carcinoma. Br J Dermatol 2003;148:892-897.

69 Hatta N, Hirano T, Kimura T, et al. Molecular diagnosis of basal cell carcinoma and other basaloid cell neoplasms of the skin by the quantification of Gli1 transcript levels. J Cutan Pathol 2005;32: 131-136.

70 Regl G, Kasper M, Schnidar H, et al. Activation of the BCL2 promoter in response to hedgehog/GLI1 signal transduction is predominantly mediated by GLI2. Cancer Res 2004;64:7724-7731.

71 Cui C, Elsam T, Tian Q, et al. Gli proteins up-regulate the expression of basonuclin in basal cell carcinoma. Cancer Res 2004;64:5651-5658.

72 Eichberger T, Regl G, Ikram MS. FOXE1, a new transcription target of GLI2 is expressed in human epidermis and basal cell carcinoma. J Invest Dermatol 2004;122:1180-1187.

73 The MT, Wong ST, Neill GW, et al. FOXM1 is a downstream target of Gli1 in basal cell carcinomas. Cancer Res 2002;62:4773-4780.

74 Regl G, Kasper M, Schnidar H, et al. The zinc-finger transcription factor GLI2 antagonizes contact inhibition and differentiation of human epidermal cells. Oncogene 2004;23:1263-1274.

75 Tas S, Avci O. Induction of the differentiation and apoptosis of tumor cells in vivo with efficiency and selectivity. Eur J Dermatol 2004;14:96-102.

76 Reifenberger J, Wolter M, Weber RG, et al. Missense mutations in $\mathrm{SMOH}$ in sporadic basal cell carcinomas of the skin and primitive neuroectodermal tumors of the central nervous system. Cancer Res 1998;58: 1798-1803.

77 Reifenberger J, Wolter M, Knobbe SB, et al. Somatic mutations in the PTCH, SMOH, SUFUH and TP53 genes in sporadic basal cell carcinomas. Br J Dermatol 2005;152:43-51.

78 Crowson AN, Pilavdzic D, Stranc M, et al. Expression of p21 ${ }^{\mathrm{WAF} 1 / \mathrm{CIP} 1}$ in aggressive-versus non-aggressive- growth basal cell carcinoma: a comparative study (Abstract). Lab Invest 1999;79:56A.

79 McIntosh LM, Jackson M, Mantsch $\mathrm{HH}$, et al. Chemical analysis of basal cell carcinomas by infrared microscopy : possible diagnostic applications (Abstract). Lab Invest 1999;79:60A.

80 McIntosh LM, Mansfield JR, Crowson AN, et al. Pathological diagnosis of basal cell carcinoma by infrared spectroscopy (Abstract). Proceedindgs for Investigative Dermatology 60th Annual Meeting, May 5-9, Chicago, IL, 1999, p 643A.

81 McIntosh LM, Jackson M, Mantsch HH, et al. Infrared spectra of basal cell carcinomas are distinct from nontumor-bearing skin components. J Invest Dermatol 1999;112:951-956.

82 McIntosh LM, Summers R, Jackson M, et al. Noninvasive diagnosis of skin tumors by near infrared spectroscopy (Abstract). J Invest Dermatol 2000; 112:670.

83 McIntosh LM, Summers R, Jackson M, et al. Towards non-invasive screening of skin lesions by nearinfrared spectroscopy. J Invest Dermatol 2001;116: 175-181.

84 Fan H, Oro AE, Scott MP, et al. Induction of basal cell carcinoma features in transgenic human skin expressing Sonic Hedgehog. Nat Med 1997;3:788-792.

85 Shea CR, McNutt NS, Volkenandt M, et al. Overexpression of p53 protein in basal cell carcinomas of human skin. Am J Pathol 1992;141:25-29.

86 De Rosa G, Saibano S, Barra E, et al. p53 protein in aggressive and non-aggressive basal cell carcinoma. J Cutan Pathol 1993;20:429-434.

87 Bayer-Garner IB, Dilday B, Sanderson RD, et al. Syndecan-1 expression is decreased with increasing aggressiveness of basal cell carcinoma. Am J Dermatopathol 2000;22:119-122.

88 McCormack CJ, Kelly JW, Dorevitch AP. Differences in age and body site distribution of the histological subtypes of basal cell carcinoma. A possible indicator of different causes. Arch Dermatol 1997;133:593-596.

89 Woods SG. Basal cell carcinoma in the black population. Int J Dermatol 1995;34:517-518.

90 Bavinck JNB, de Boer A, Vermeer BJ, et al. Sunlight, keratotic skin lesions and skin cancer in renal transplant recipients. $\mathrm{Br} \mathrm{J}$ Dermatol 1993;129: 242-249.

91 Rady RL, Yen A, Rollefson JL, et al. Herpes virus-like DNA sequences in non-Kaposi's sarcoma skin lesions of transplant patients. Lancet 1995;345:1339-1340.

92 Sitz KV, Keppen M, Johnson DF. Metastatic basal cell carcinoma in acquired immunodeficiency syndromerelated complex. JAMA 1987;257:340-343.

93 Kohchiyama A, Oka D, Ueki H. Expression of human lymphocyte antigen (HLA)-DR on tumor cells in basal cell carcinoma. J Am Acad Dermatol 1987;16:833-838.

94 Cohen MS, Rogers GS. The significance of mast cells in basal cell carcinoma. J Am Acad Dermatol 1995;33: 514-517.

95 Satti MB, Azzopardi JG. Amyloid deposits in basal cell carcinoma of the skin. J Am Acad Dermatol 1990;22:1082-1087.

96 Olsen KE, Westermark P. Amyloid in basal cell carcinoma and seborrheic keratosis. Acta Derm Venereol (Stockholm) 1994;74:273-275.

97 Sahin AA, Ro JY, Grignon DJ, et al. Basal cell carcinoma with hyaline inclusions. Arch Pathol Lab Med 1989;113:1015-1018. 
98 Zamecnik M, Skalova A, Michal M. Basal cell carcinoma with collagenous crystalloids. Arch Pathol Lab Med 1996;120:581-582.

99 Kallioinen M, Autio-Harmainen A, Dammert K, et al. Discontinuity of the basement membrane in fibrosing basocellular carcinomas and basosquamous carcinomas of the skin: an immunohistochemical study with human laminin and type IV collagen antibodies. J Invest Dermatol 1984;82:248-251.

100 Barsky SH, Grossman DA, Bhuta S. Desmoplastic basal cell carcinomas possess unique basement membrane-degrading properties. J Invest Dermatol 1987;88:324-329.

101 Iida J, Wilhelmson KL, Price MA, et al. Membrane type-I matrix metalloproteinase promotes human melanoma invasion and growth. J Invest Dermatol 2004;122:167-176.

102 Jones JCR, Steinman HK, Goldsmith BA. Hemidesmosomes, collagen VII, and intermediate filaments in basal cell carcinoma. J Invest Dermatol 1989;93:662-671.

103 Bouffard D, Duncan LM, Howard CA, et al. Actinbinding protein expression in benign and malignant melanocytic proliferations. Hum Pathol 1994;25: $709-714$.

104 Duncan LM, Bouffard D, Howard C, et al. In situ distribution of alpha 2 beta 1 and alpha-actinin in melanocytic proliferations. Mod Pathol 1996;9:938-943.

105 Brooke JD, Fitzpatrick JE, Golitz LE. Papillary mesenchymal bodies: a histologic finding useful in differentiating trichoepitheliomas from basal cell carcinomas. J Am Acad Dermatol 1989;21:523-528.
106 Kirchmann TT, Prieto VG, Smoller BR. CD34 staining pattern distinguishes basal cell carcinoma from trichoepithelioma. Arch Dermatol 1994;130:589-592.

107 Smoller BR, van de Rijn M, Lebrun D, et al. Bcl-2 expression reliably distinguishes trichoeplthelioma from basal cell carcinomas. Br J Dermatol 1994;13: 28-31.

108 Bayer-Garner IB, Givens V, Smoller BR. Immunohistochemical staining for androgen receptors: a sensitive marker of sebaceous differentiation. Am J Dermatopathol 1999;21:426-431.

109 Hassanein AM. Sebaceous carcinoma and the Tantigen. Semin Cutan Med Surg 2004;23:62-72.

110 Ansai S, Mitsuhashi Y, Kondo S, et al. Immunohistochemical differentiation of extra-ocular sebaceous carcinoma from other skin cancers. J Dermatol 2004; 31:998-1008.

111 Izikson L, Bhan A, Zembowicz A. Androgen receptor expression helps to differentiate basal cell carcinoma from benign trichoblastic tumors. Am J Dermatopathol 2005;27:91-95.

112 Crowson AN, Magro CM, Mihm Jr MC. The Melanocytic Proliferations: A Comprehensive Textbook of Pigmented Lesions. John Wiley and Sons: New York, 2001.

113 Mott RT, Smoller BR, Morgan MB. Merkel cell carcinoma: a clinicopathological study with prognostic implication. J Cutan Pathol 2004;31:217-223.

114 Sebastien TS, Nelson BR, Lowe L, et al. Microcystic adnexal carcinoma. J Am Acad Dermatol 1993;29: 840-845. 